\title{
Characterization of anti-silencing factor 1 in Leishmania major
}

\author{
Ricardo Scher ${ }^{1,2}$, Juliana Bório Ferreira Garcia', Bruno Pascoalino³, \\ Sergio Schenkman ${ }^{3}$, Angela Kaysel Cruz ${ }^{1 /+}$
}

\begin{abstract}
'Departamento de Biologia Celular e Molecular e Bioagentes Patogênicos, Faculdade de Medicina de Ribeirão Preto, Universidade de São Paulo, Av. Bandeirantes 3900, 14049-904 Ribeirão Preto, SP, Brasil ²Departamento de Morfologia, Centro de Ciências Biológicas e da Saúde, Universidade Federal de Sergipe, Aracaju, SE, Brasil

${ }^{3}$ Departamento de Microbiologia, Imunologia e Parasitologia, Universidade Federal de São Paulo, São Paulo, SP, Brasil
\end{abstract}

\begin{abstract}
Anti-silencing factor 1 (ASF1) is a histone chaperone that contributes to the histone deposition during nucleosome assembly in newly replicated DNA. It is involved in chromatin disassembly, transcription activation and in the cellular response to DNA damage. In Leishmania major the ASF1 gene (LmASF1) is located in chromosome 20 and codes for a protein showing $67 \%$ of identity with the Trypanosoma brucei TbASF1a. Compared to orthologous proteins, LmASF1 conserves the main residues relevant for its various biological functions. To study ASF1 in Leishmania we generated a mutant overexpressing LmASF1 in L. major. We observed that the excess of LmASF1 impaired promastigotes growth rates and had no impact on cell cycle progress. Differently from yeast, ASF1 overproduction in Leishmania did not affect expression levels of genes located on telomeres, but led to an upregulation of proteins involved in chromatin remodelling and physiological stress, such as heat shock proteins, oxidoreductase activity and proteolysis. In addition, we observed that LmASF1 mutant is more susceptible to the DNA damaging agent, methyl methane sulphonate, than the control line. Therefore, our study suggests that ASF1 from Leishmania pertains to the chromatin remodelling machinery of the parasite and acts on its response to DNA damage.
\end{abstract}

Key words: Leishmania major - anti-silencing factor 1 - histone chaperone

Leishmania spp is a member of the Trypanosomatidae family and a parasitic protozoa and digenetic eukaryote of medical and veterinary relevance. Leishmania undergoes several changes to adapt to and survive in different hostile environments, namely the insect vector digestive tract and the vertebrate host's macrophagic phagolysosomes. For that a tight and agile control of gene expression is required.

Differently from most of the eukaryotes, these parasites have polycistronic transcription and control of gene expression occurs primarily at the posttranscriptional level (reviewed by Clayton 2002, Martinez-Calvillo et al. 2010). Likewise other eukaryotes, in these parasites the chromatin structure modulates the access of proteins to the DNA, which ultimately regulates different aspects of gene expression, DNA processing, replication and double-stranded DNA repair (Navarro et al. 1999, Elias et al. 2001, Gontijo et al. 2003, McNairn \& Gilbert 2003).

Anti-silencing factor 1 (ASF1) is a histone chaperone that together with chromatin assembly factor (CAF)-1 adds histones $\mathrm{H} 3$ and $\mathrm{H} 4$ onto newly replicated DNA (Tyler et al. 2001). This suggests a role for ASF1 in chro-

Financial support: FAPESP (99/12403-3, 06/50323-7)

RS was supported by a fellowship from CAPES and JBFG and BP by FAPESP. RS and JBFG contributed equally to this work.

+ Corresponding author: akcruz@fmrp.usp.br

Received 4 August 2011

Accepted 11 January 2012 matin assembly regulation (Loyola \& Almouzni 2004, Zhang et al. 2005). ASF1 can be involved either in gene activation or transcriptional repression; it depends on the factors it interacts with (Sutton et al. 2001, Schwabish \& Struhl 2006, Adkins et al. 2007, Takahata et al. 2009, Varv et al. 2010). In different eukaryotes deletion of ASF1 alters response to DNA damage and DNA replication blocking agents (Le et al. 1997, Tyler et al. 1999) and leads to gross chromosomal rearrangements (Prado et al. 2004) and even to cell death (Sanematsu et al. 2006).

The increased susceptibility of chromatin-assembly factor mutants to DNA-damaging agents may be an effect of the direct role of these factors in modulating chromatin structure (Mello et al. 2002). In addition, an association between ASF1 and genomic stability has been provided by the identification of a dynamic interaction between ASF1 and the Rad53 DNA damage checkpoint protein. Also, activation of ASF1 may be an important cellular response to DNA damage and replication stress (Emili et al. 2001, Hu et al. 2001). When DNA damage occurs, ASF1 is recruited to the lesion site where it may disrupt the $\mathrm{H} 3 / \mathrm{H} 4$ tetramer. This results in nucleosome eviction and allows access of the repair machinery to unencumbered DNA (Canfield et al. 2009).

In Leishmania species ASF1 roles have not been investigated, although orthologous genes have been annotated in the sequenced genomes (tritrypdb.org). In another trypanosomatid, Trypanosoma brucei, the participation of ASF1 in the machinery that regulates spindle assembly and S-phase progression has been described ( $\mathrm{Li}$ et al. 2007). Therefore, given that ASF1 is associated with gene expression in other eukaryotes and that chromatin modifications are relevant for controlling 
transcription in trypanosomatids (Green \& Almouzni 2003, Figueiredo et al. 2009) we investigated Leishmania major's ASF1. Our aim was to understand which of the known functions of ASF1 from other eukaryotes are shared by this parasite's protein.

\section{MATERIALS AND METHODS}

Parasites culture and transfection - L. major MHOM/ IR/83/IR (LmCC-1) promastigotes were grown at $26^{\circ} \mathrm{C}$ in M199 medium supplemented with 10\% heat inactivated foetal calf serum, HEPES $(0.04 \mathrm{M})$, adenine $(0.1 \mathrm{mM})$, biotin $(0.1 \%)$, haemin $(0.25 \%)$, penicillin $\left(2.5 \mathrm{U} / \mathrm{mL}^{-1}\right)$, streptomycin $\left(2.5 \mathrm{mg} / \mathrm{mL}^{-1}\right)$. Transfection experiments were conducted as described elsewhere (Kapler et al. 1990). Mutants overexpressing ASF1, Lm[pX63NEO$A S F 1]$ and $\mathrm{Lm}[p X 63 N E O]$, which bears the vector with no insert, were selected and cultured in the presence of G418. Increasing concentration of drug of selection (G418) was used to raise plasmid copy number and obtain higher levels of expression of episomal genes. G418 $\mathrm{LD}_{50}$ was determined $\left(1 \mu \mathrm{g} \cdot \mathrm{mL}^{-1}\right)$; we worked on a range of two-100 folds the $\mathrm{LD}_{50}$.

Plasmid constructs - A 1,246 bp fragment from pUCE8HH5.4, containing LmASF1 ORF and its 5' and 3'UTR, was obtained after AatII digestion. This plasmid was constructed with a $5.4 \mathrm{~kb}$ HindIII fragment subcloned from a cosmid, it has been described elsewhere (Pedrosa et al. 2001). pX63NEO-ASF1, which was used to overexpress the $L m A S F 1$ in $L$. major, was obtained by insertion of the 1,246 bp fragment into pX63NEO AatIIdigested (LeBowitz et al. 1991).

$R N A$ extraction and northern blotting hybridization RNA from L. major in vitro cultures was extracted with Trizol $^{\circledR}$ reagent following the manufacturer's protocol. Twenty micrograms of total RNA of each sample were fractionated on $2.2 \mathrm{M}$ formaldehyde $1.2 \%$ agarose gel and transferred to a hybond-N+ nylon membrane. Subsequent steps for probe labelling and northern hybridization were conducted according to established protocols (Feinberg \& Vogelstein 1983).

Flow cytometry analysis and propidium iodide staining - L. major control and ASF1 overexpressor cells were prepared according to Shapiro (Shapiro et al. 1984). The DNA content of PI-stained cells was analyzed with a FACScan analytical flow cytometer using the Cellquest software (BD Biosystems).

Total protein cell extracts and two-dimensional gel electrophoresis $(2 D)$ - Cells $\left(1 \times 10^{9}\right)$ in late-log phase of axenic growth were pelleted $\left(2,000 \mathrm{~g} / 10 \mathrm{~min} / 4^{\circ} \mathrm{C}\right)$, washed twice with $1 \mathrm{x}$ phosphate buffered saline (PBS) $(\mathrm{pH}$ 7.0) and ressuspended in $1 \mathrm{~mL} 0.1 \mathrm{x}$ PBS containing protease inhibitors (Complete, Roche) for cell lysis. Cell extracts were submitted to five freeze-thaw cycles in liquid $\mathrm{N}_{2} /$ water bath at $30^{\circ} \mathrm{C}$ and cellular debris were removed by two rounds of centrifugation $(10,000 \mathrm{~g} / 10$ min, at $4^{\circ} \mathrm{C}$ ). The supernatants were precipitated with $5 \mathrm{~mL} 0.1 \times$ PBS and trichloroacetic acid (TCA) at $4^{\circ} \mathrm{C}$ for $2 \mathrm{~h}$. Precipitates were collected by centrifugation at $10,000 \mathrm{~g}$ followed by two washes with frozen acetone.
Proteins were solubilised in $300 \mu \mathrm{L}$ of rehydration buffer [7 M urea, $2 \mathrm{M}$ thiourea, 4\% CHAPS (w/v)] plus nuclease solution (160 units of DNAse and $125 \mu \mathrm{g}$ RNAse) and $10 \mathrm{mM} \mathrm{MgCl}$ and incubated for $12 \mathrm{~h}$ at room temperature. Protein concentration was determined by the Bradford method (Bradford 1976).

Independent cultures of $\mathrm{Lm}[p X 63 N E O]$ and $\mathrm{Lm}[p X 63 N E O-A S F 1]$ were used for comparative analysis by $2 \mathrm{D}$ gel electrophoresis Immobiline DryStrip gels (13 cm: 4-7, GE-HealthCare) were rehydrated in $700 \mu \mathrm{g}$ of parasite protein sample. Isoelectric focusing (IEF) was carried out at $20^{\circ} \mathrm{C}$ with maximum current setting at $50 \mu \mathrm{A}$ per strip, using an active two-step rehydration system of $2 \mathrm{~h}$ at $0 \mathrm{~V}$ and of $10 \mathrm{~h}$ at $30 \mathrm{~V}$, directly in ceramic strip holders, and then focused on an IPGphor IEF unit (GE HealthCare). Conditions for IEF were: $1 \mathrm{~h}$ at $500 \mathrm{~V}$, $1 \mathrm{~h}$ at $1,000 \mathrm{~V}, 1 \mathrm{~h}$ at $2,000 \mathrm{~V}, 1 \mathrm{~h}$ at 4,000 and at 8,000 $\mathrm{V}$ until voltage reached $55,000 \mathrm{Vh}$. Focused $\mathrm{pH}$ gradient strips were then fractionated in sodium dodecyl sulfate polyacrylamide gel electrophoresis (SDS-PAGE) $(12.5 \%$ polyacrylamide) according to the GE-HealthCare manual. Gel fixation and colloidal Coomassie staining were performed according to (Neuhoff et al. 1988). Gels were stored at $4^{\circ} \mathrm{C}$ in $25 \%$ ammonium sulfate and scanned with ImageScanner III (GE-HealthCare). Comparative analysis of digitized proteome maps was conducted with ImageMaster Platinum v7.0 software (GE-HealthCare). Differences higher than one-and-a-half-fold in the pattern and/or intensity of protein spots of analyzed strains were identified by pairwise comparison using gel images (Supplementary data). The proteins were identified by mass spectrometry using a MALDI TOF-TOF (4700 Proteomics Analyzer, Applied Biosystems).

Real-time PCR (RT-PCR) - Relative quantification RT-PCR was performed using an ABI 7500 Sequence Detection System (Applied-Biosystems) in the presence of SYBR-green. The optimization of the RT-PCR reaction was performed according to the manufacturer's instructions (Applied-Biosystems, User Bulletin 2 applied to the SYBR-Green I core reagent protocol). The reactions were performed as technical and biological triplicates using SYBR Green (SYBRGreen PCR Master Mix, Applied Biosystems). Final concentration of oligonucleotides in the reaction was $200 \mathrm{nM}$ and the identification of the 44 targeted transcripts and primers sequences are provided as Supplementary data. GLucose-6-phosphate dehydrogenase was used as the control of constitutive gene expression. To evaluate the efficiency of amplification reaction of each gene-target, a standard curve was generated using 10 -fold dilutions of cDNA. The relative expression was analyzed by $2^{-\Delta \Delta C \mathrm{~T}}$ method.

Production of polyclonal antiserum anti-ASF1 and western blotting analysis - Rabbit serum was obtained by immunization with a recombinant polypeptide corresponding to the T. brucei ASF1 gene. This was PCR amplified using Asf-FowNdeI (5'-CATATGAGATACAACCAATT) and Asf-RevBamHI (5'-GGATCCTCATCTGGGTTCAAGTGC) primers from the parasite genomic DNA and cloned in NdeI-BamHI sites pET14b. 
After induction with $0.5 \mathrm{mM}$ IPTG for $12 \mathrm{~h}$ at $37^{\circ} \mathrm{C}$, the recombinant protein was extracted with BugBuster Protein Extraction Reagent (Novagen) and purified by affinity chromatography on Ni-Agarose (Qiagen). Specific antibodies were purified with the same ASF1 used for the immunization. The recombinant protein was immobilized in a cyanogen bromide-agarose beads (GE Healthcare) and after washes with 10 column volumes it has been eluted with $0.1 \mathrm{M}$ triethylamine, $\mathrm{pH} 11$. The fractions were neutralized to $\mathrm{pH} 8$ with Tris- $\mathrm{HCl} 1 \mathrm{M} \mathrm{pH}$ 7.4 and dialyzed against PBS.
For western blots, total protein was extracted from 1 x $10^{7}$ parasites. Samples were fractionated in $12.5 \%$ SDSPAGE, transferred to nitrocellulose membranes. Total proteins were visualized by staining with Ponceau-S and incubated with primary antibody in blocking solution. Antibody dilutions used were 1:500 to 1:1,000. The membrane was washed three times for 10 min with PBS, $0.1 \%$ Tween20 and incubated with protein A 1:10,000 or anti-rabbit $\operatorname{IgG}(1: 20,000)$ both conjugated to HRP (Invitrogen) for 45 $\min$. The membrane was treated and bond antibodies developed following ECL kit instructions (ECL, Millipore).

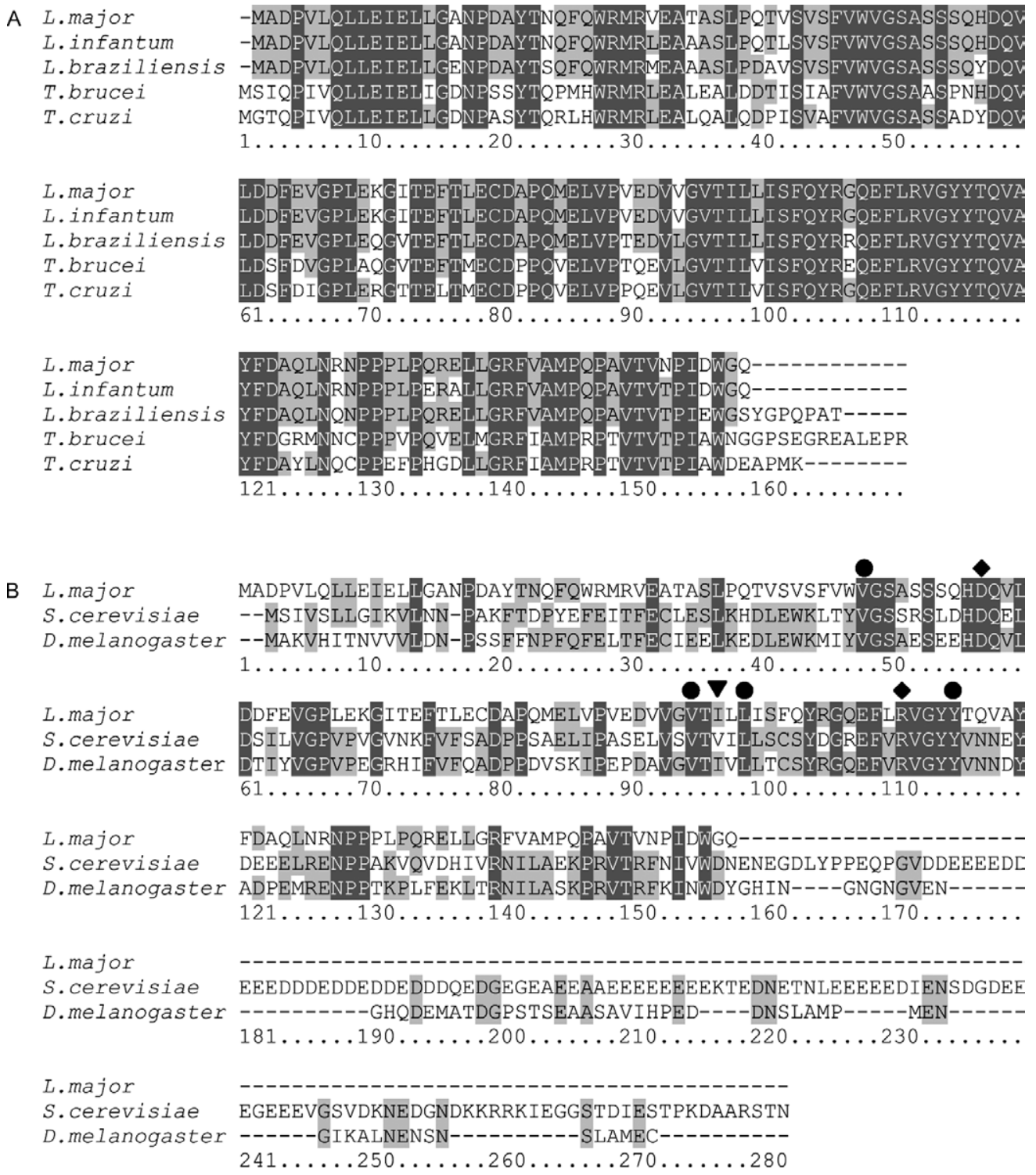

Fig. 1: conservation of anti-silencing factor 1 (ASF1) sequence. A: alignment of ASF1 from Trypanosomatidae showing high conservation in aminoacid residues ( $67 \%)$; B: alignment of Leishmania major, Saccharomyces cerevisiae and Drosophila melanogaster ASF1 showing conserved residues of $\mathrm{N}$-terminal region. Identical residues are shaded dark grey while conserved residues are shaded light grey. The symbol $(\bullet)$ means the amino acids V45, V92, L96 and Y112 and ( $\bullet$ means the residues D54 and R108. The substitution V94I is indicated by the arrow head. The accessions of ASF1 sequences are: L. major, AAK28282.1, Leishmania infantum, CAM67383.1, Leishmania braziliensis, XP_001564694.1, Trypanosoma brucei, CAJ15961.1, Trypanosoma cruzi, XM_810961.1, S. cerevisiae, AAC37512.1 and D. melanogaster, AAF15354.1. The aminoacid positions correspond to D. melanogaster ASF1 sequence. 
Western blot signal quantification by ImageJ - We selected the band indicated by "LmASFI" (at the right end of panel C) for quantification. ImageJ square tool was selected and used to determine the number of pixels per band using the tool named "plot profile". The number of pixels obtained per band was subtracted from background pixels. The relative expression was calculated by dividing the value obtained for the signal detected in the transfectant by that observed in the control strain. Normalization of the values was conducted using the corresponding Ponceau-stained membrane.

\section{RESULTS}

L. major ASF1 sequence conservation - The ASF1 primary sequence is highly conserved throughout evolution, as it is shown by the in silico comparative analysis of the ASF1 homologues among trypanosomatids, Saccharomyces cerevisiae and Drosophila melanogaster (Fig. 1A, 1B). L. major ASF1 (LmjF20.0050) comprises 158 amino acids and displays $67 \%$ sequence identity with the T. brucei ASF1a (Tb927.1.630). The N-terminal domain is highly conserved between Leishmania, S. cerevisiae and D. melanogaster, but BLAST analysis revealed that the ASF1 C-terminal region from trypanosomatids lacks the long poly-acidic tract found in yeast (Fig. 1B).

Effects of LmASF1 overexpression over growth rate and cell cycle - The detection of LmASFI transcript in promastigotes by northern blotting was only possible when at least $20 \mu \mathrm{g}$ of total RNA was used, indicating that its endogenous level is low. We observed that the LmASF1 transfectant ( $\mathrm{Lm}[\mathrm{p} X 63 \mathrm{NEO}-A S F 1])$ has higher levels of $L m A S F 1$ transcript as compared to other transcripts. A positive correlation between drug concentration and increment of transcript levels was detected (Fig. 2A). The larger RNAs hybridizing with the ASF1 probe are probably read-through transcripts, commonly found in episomal transcription in Leishmania. Relative expression of the LmASF1 transcript in log phase promastigotes is 90.5 times higher in the overexpressor as compared to the control line (Fig. 2B). Interestingly, the protein level seeing as $18 \mathrm{KDa}$ band detected by western blot using an anti-T. brucei ASF1 increased, but the increment did not seem so high (Fig. 2C). Image quantification revealed that ASF1 was at least 3.0 fold augmented in the overexpressor as compared to the control line $\mathrm{Lm}[\mathrm{pX}$ X3NEO]. Quantification was conducted with the western band signals from cells kept at $100 \times \mathrm{LD}_{50}$ to be comparable to the quantitative RT-PCR estimation of the transcript (Fig. 2C).

In addition overexpression of LmASF1 decreased slightly the growth rate of promastigotes in axenic culture (Fig. 3A). The doubling time of the overexpressor mutant is $8.67 \mathrm{~h}$ as compared to $6.84 \mathrm{~h}$ of the control line. We did not witness significant changes of the cell cycle progression after submitting non-synchronized populations of ASF1 overexpressor as compared with the control transfectants (Fig. 3B).

Changes in gene expression pattern in the LmASF1 overexpressor - Because the $S$. cerevisiae's ASF1 is an ASF that releases the expression of genes located at the very end of the chromosomes, we investigated whether a similar role is played by its $L$. major orthologue, the LmASF1. We evaluated the transcript levels of 42 genes located in various chromosomes by comparing $\mathrm{Lm}[p X 63 N E O-A S F 1]$ and $\mathrm{Lm}[p X 63 N E O]$, most of them from the chromosomes' extremities (see distance of each gene from its telomeric end) (Table I). We found that expression of only five genes was affected by ASF1 overexpression (Table I). Among the few modulated genes, only one, the second annotated gene on chromosome 4 (LmjF04.0020), is less than $16 \mathrm{~kb}$ far from a telomere, as shown on Table I.
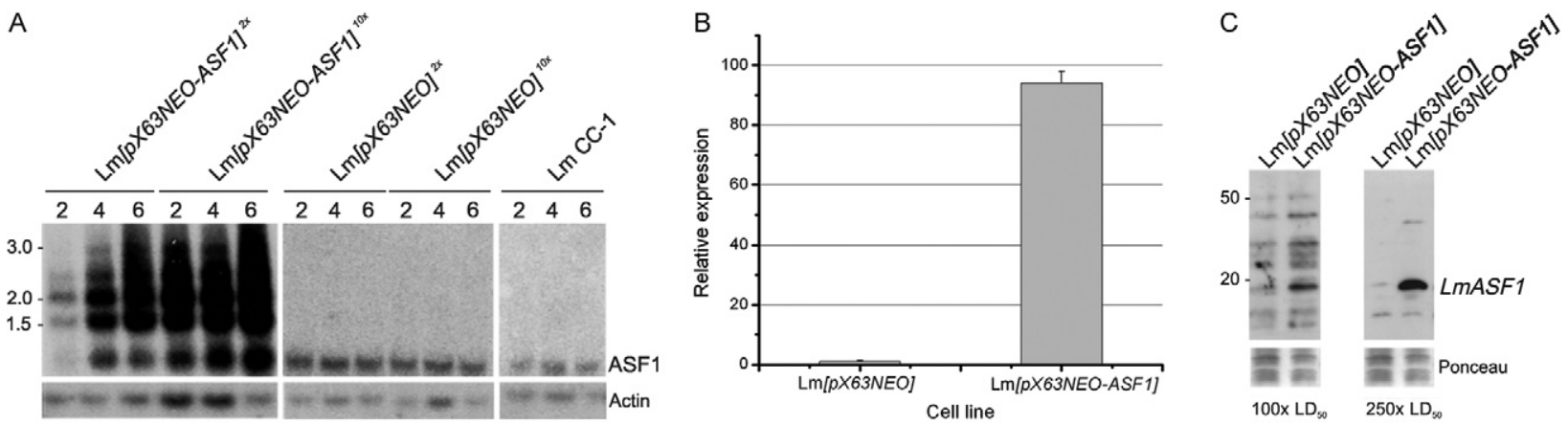

Fig. 2: anti-silencing factor 1 (ASF1) overexpression in Leishmania major. A: total RNA was extracted from promastigotes after two, four and six days in axenic culture (at the top of panel A: 2, 4 and 6, respectively) and $20 \mu \mathrm{g}$ was fractionated in denaturing agarose gel, transferred to nylon membranes and hybridized with radiolabeled ASF1 probe. The left panel shows increasing amounts of $L m A S F 1$ transcript in log phase overexpressor in two conditions of drug pressure ( $\mathrm{Lm}[p X 63 N E O-A S F 1]^{2 \mathrm{x}}$ and $\left.\mathrm{Lm}[\mathrm{p} X 63 N E O-A S F 1]^{10 x}\right)$ as compared to control lines (control transfectant $\mathrm{Lm}[p X 63 N E O]^{2 x}, \mathrm{Lm}[p X 63 N E O]^{10 x}$ and $\left.\mathrm{LmCC}-1\right)$ which are presented in mid and right panels, respectively. A fragment of actin gene was radiolabeled and used as a control of RNA loading (strip shown at the bottom of panels). Numbers shown in superscript mode refer to the drug pressure used in each experiment (times the $\mathrm{LD}_{50}$ of G418); B: relative expression of $L m A S F 1$ revealed by real-time polymerase chain reaction. The parasites were kept in media containing $100 \mathrm{LD}_{50}$ of $\mathrm{G} 418 ; \mathrm{C}$ : immunoblotting of cell extracts from promastigotes of $L$. major overexpressor, $\mathrm{Lm}[p X 63 N E O-A S F 1]$, and control line $\mathrm{Lm}[p X 63 N E O]$ in two conditions of drug pressure $\left(100 \mathrm{x} \mathrm{LD}_{50}\right.$, left panel and $250 \mathrm{x} \mathrm{LD}$, right panel) was probed with affinity purified antiserun to Trypanosoma brucei ASF1. 

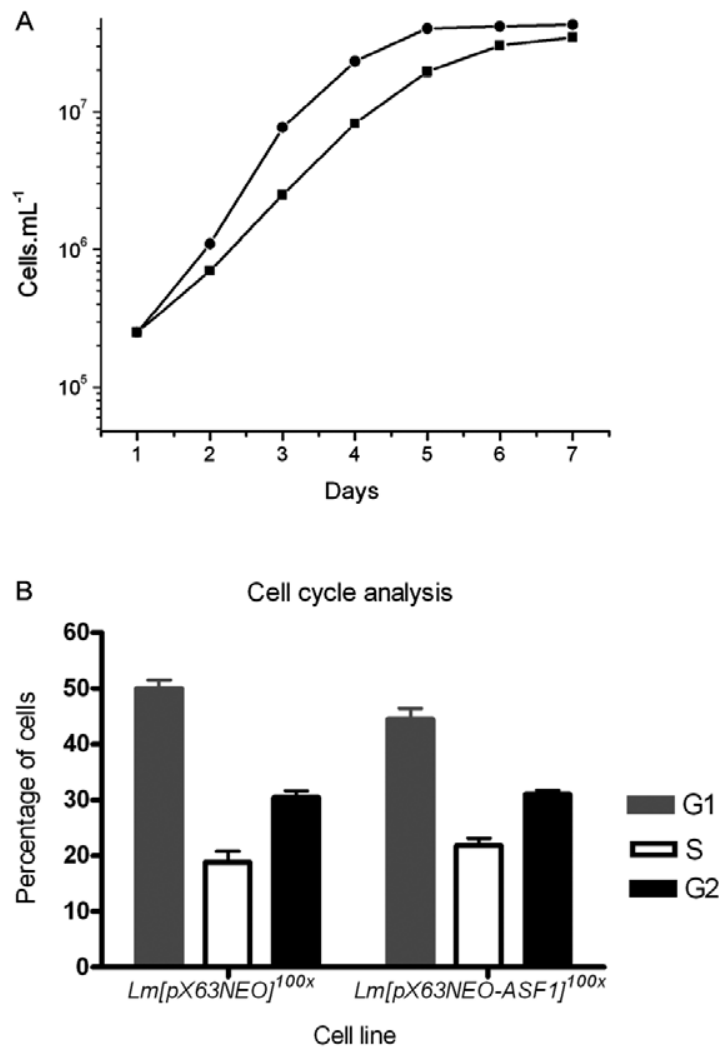

Fig. 3: growth and cell cycle of $L m A S F 1$ overexpressor. A: growth curves of Leishmania major anti-silencing factor 1 (ASF1) overexpressor $\mathrm{Lm}[p X 63 N E O-A S F 1]^{100 x}$ (घ) and control transfectant $\operatorname{Lm}[p X 63 N E O]^{100 x}(\bullet)$. Each point in the curves shown represents the mean and standard error from triplicates obtained from one representative experiment; B: FACS analysis of $L$. major ASF1 overexpressor $\left(\mathrm{Lm}[p X 63 N E O-A S F 1]^{100 x}\right.$ and control line $\left(\mathrm{Lm}[p X 63 N E O]^{100 x}\right)$. Cells were rescued on early logarithmic phase of culture and stained with pI. The bars represent the averages of at least five independent experiments. The error bars indicate the standard deviation. The statistic test used was two-way analysis of variance (GraphPad Prism 4.00) and the variation between the cell lines was not significant. Numbers shown in superscript mode refer to the applied drug pressure (times the $\mathrm{LD}_{50}$ of G418). Gray, white and black bars correspond to the cell cycle phases G1, S and G2, respectively.

We also evaluated the overall protein profile modifications triggered by the overexpression of ASF1 in the L. major ASF1 mutant. From three independent cultures of each cell line, protein was extracted and fractionated by two-dimensional gel electrophoresis and subsequently identified by mass spectrometry (Supplementary data). The number of identified spots in the 2D gel triplicates varied between 638-672 for the $\mathrm{Lm}[\mathrm{p} X 63 \mathrm{NEO}$ ] and 725990 for $\mathrm{Lm}[\mathrm{p} X 63 N E O-A S F 1]$. We detected 19 proteins that were differentially expressed. Nine proteins were upregulated in the mutant and 10 were downregulated (Table II). Noteworthy, when we grouped the differentially expressed genes by Gene Ontology website terms (GO) (geneontology.org) we observed that six of them were either classified as heat-shock (HS), HS-related proteins or stress induced proteins (LmjF11.0350, LmjF26.1240, LmjF30.2460,

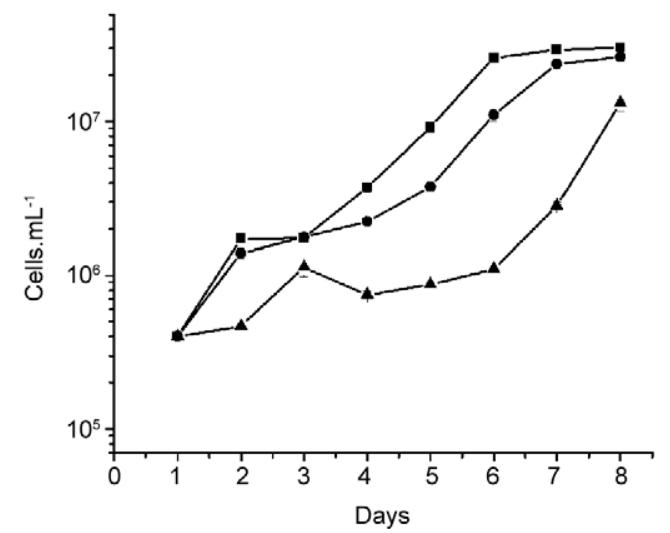

Fig. 4: growth impairment of Leishmania anti-silencing factor 1 (ASF1) overexpressors under methyl methane sulfonate (MMS) treatment. Leishmania major parental line (LmCC-1) (ロ), ASF1 overexpressors $\operatorname{Lm}[p X 63 N E O-A S F 1]^{10 x}(\bullet)$ and $\operatorname{Lm}[p X 63 N E O-A S F 1]^{50 x}(\boldsymbol{\Delta})$ were maintained in the presence of MMS $(0.005 \%)$ and monitored for cell growth for eight days. Numbers shown in superscript mode refer to the drug pressure used (times the $\mathrm{LD}_{50}$ of G418). Each point in the curves shown represents the mean and standard error from triplicates obtained from one representative experiment.

Lmj28.2770, LmjF36.2030, LmjF08.1110), one protein is involved in proteolytic processes (LmjF33.2770), two have been identified as putative nucleosome assembly proteins (coded by genes LmjF29.2340 and LmjF19.0440) and three are involved in oxidoreductase activity (LmjF23.0040, LmjF23.0360, LmjF07.0430) (Table II). The other seven proteins identified were classified in diverse groups of GO categories (Table II).

ASF1 mutant is oversensitive to methyl methane sulfonate (MMS) - To verify whether ASF1 overexpression modifies the response to DNA damaging agents, we evaluated the parasites resistance to an alkylating agent. Parasites were submitted to sub-lethal concentration of MMS $(0.005 \%)$ and promastigotes multiplication rates were estimated. There was a visible difference between the growth rate of parental cells and ASF1 overexpressor in the presence of MMS. In the $L m A S F 1$ overexpressor the lag phase was extended for five days and only on the sixth day of culture it reached the logarithmic phase of growth, which in the parental line occurred on the third day (Fig. 4).

\section{DISCUSSION}

The eukaryotic ASF1 protein is highly conserved throughout evolution (Daganzo et al. 2003, Mousson et al. 2005, Tamburini et al. 2005). Homologues of the ScASF1 have been found in the genomes of trypanosomatids (tritrypdb.org) and the involvement of the T. brucei homologue, TbASFla, in the control of spindle assembly and S-phase progression has been shown (Li et al. 2007). Nevertheless, no functional studies have been reported with Leishmania ASF1 homologues. This is the first study that presents an initial characterization of L. major ASF1.

Leishmania ASF1 amino acid sequence shows a high degree $(40 \%)$ of identity with homologues of a wide 
variety of organisms, from yeast to man (Fig. 1) (ncbi. nlm.nih.gov/). In fact, the trypanosomatid's ASF1 corresponds to the 155-conserved amino-terminal sequence of budding yeast ASF1. Interestingly, we observed conservation among residues V45, V92, L96 and Y112 (Fig. 1B), which are the ones flanking the hydrophobic groove, a potential binding site for histones and other interacting proteins (Daganzo et al. 2003, Mousson et al. 2005). The central residue in this groove is located at position 94.
Whereas in yeast this residue is a valine in Drosophila and in trypanosomatids it is an isoleucine. The hydrophobicity of the region is maintained by polar and charged residues such as D54 and R108, which are conserved in trypanosomatids. We observed that in LmASF1 all substitutions of residues that occurred in this groove and surrounding regions are conserved (Fig. 1). This region is crucial for the establishment of electrostatic interactions between the chaperone and the histone core (Mous-

\section{TABLE I}

Transcript differential expression of 42 genes by real-time polymerase chain reaction

\begin{tabular}{|c|c|c|c|}
\hline ID & Product & $\begin{array}{l}\text { Distance of } \\
\text { telomere } \\
(\mathrm{Kb})\end{array}$ & $\begin{array}{c}\text { Relative expression } \\
\mathrm{Lm}[p X 63 N E O-A S F 1] / \\
\mathrm{Lm}[p X 63 N E O]\end{array}$ \\
\hline LmjF01.0010 & Hypothetical protein conserved & 3.7 & - \\
\hline LmjF01.0020 & Hypothetical protein unknown function & 5.8 & - \\
\hline LmjF01.0810 & Calcium/potassium channel, putative & 24.75 & - \\
\hline LmjF01.0820 ${ }^{a}$ & Potassium channel subunit-like protein & 16.6 & $2.3 \mathrm{x}$ \\
\hline LmjF02.0010 & Phosphoglycan beta 1,3 galactosyltransferase 3 & 6.87 & - \\
\hline LmjF02.0180 & Phosphoglycan beta 1,2 arabidosyltransferase & 92.8 & - \\
\hline LmjF02.0190 & Phosphoglycan beta 1,3 galactosyltransferase like-protein & 97.1 & - \\
\hline LmjF03.0080 & Glycerol 3 phosphate acyltransferase & 18.8 & - \\
\hline LmjF04.0010 & Calcium translocating P-type ATPase organelle-type calcium ATPase & 4.6 & - \\
\hline LmjF04.0020 $0^{a}$ & Pteridine transporter (truncated) putative & 9.8 & $1.6 \mathrm{x}$ \\
\hline LmjF04.0030 & Camp-specific phosphodiesterase, putative & 12.7 & - \\
\hline LmjF04.0060 & DNA topoisomerase type IB small subunit & 27.7 & - \\
\hline LmjF04.1160 & Fructose 1,b biphosphatase, cytosolic putative & 43.9 & - \\
\hline LmjF04.1190 & tRNA nucleotidyltransferase putative & 18.3 & - \\
\hline LmjF04.1220 & Hypothetical protein conserved & 6.7 & - \\
\hline LmjF08.0080 & ATP-dependent DEAD/H RNA helicase putative & 21.0 & - \\
\hline LmjF09.0070 & RNA helicase putative & 17.2 & - \\
\hline LmjF11.0010 & Hypothetical protein conserved & 1.9 & - \\
\hline LmjF11.0020 & Hypothetical protein conserved & 2.9 & - \\
\hline LmjF11.0030 & Hypothetical protein conserved & 4.6 & - \\
\hline LmjF11.1360 & Hypothetical protein conserved & 10.6 & - \\
\hline LmjF11.1370 & Hypothetical protein conserved & 7.1 & - \\
\hline LmjF11.1380 & Hypothetical protein conserved & 4.0 & - \\
\hline LmjF18.0010 & Hypothetical protein conserved & 4.7 & - \\
\hline LmjF18.0020 & Diphosphomevalonate decarboxylase, putative & 7.9 & - \\
\hline LmjF18.0030 & Hypothetical protein conserved & 9.7 & - \\
\hline LmjF18.1660 & Gamma-glutamylcysteine synthetase & 10.0 & - \\
\hline LmjF18.1670 & Hypothetical protein, unknown function & 4.0 & - \\
\hline LmjF20.0020 & Hypothetical protein conserved & 7.5 & - \\
\hline LmjF20.0030 & Hypothetical protein conserved & 9.4 & - \\
\hline LmjF20.0040 & Hypothetical protein conserved & 13.2 & - \\
\hline LmjF20.0050 & Anti-silencing protein 1 -like protein & 15.1 & $90.5 x$ \\
\hline LmjF20.0060 & Hypothetical protein conserved & 19.6 & - \\
\hline LmjF20.0070 & Hypothetical protein conserved & 21.3 & - \\
\hline $\mathrm{LmjF} 20.0080^{a}$ & Hypothetical protein conserved & 24.9 & $0.57 \mathrm{x}$ \\
\hline $\mathrm{LmjF}^{20.0090^{a}}$ & Hypothetical protein conserved & 30.3 & $0.62 \mathrm{x}$ \\
\hline LmjF20.160 & Hypothetical protein conserved & 3.2 & - \\
\hline LmjF22.1670 & Hypothetical protein conserved & 32.8 & - \\
\hline LmjF23.0290 & Hypothetical protein conserved & 108.2 & - \\
\hline LmjF23.0300 & Tryptophanyl-tRNA synthase, putative & 110.1 & - \\
\hline LmjF23.0310 & Hypothetical protein conserved & 112.8 & - \\
\hline LmjF23.0320 ${ }^{a}$ & Hypothetical protein conserved & 118.2 & $0.48 \mathrm{x}$ \\
\hline LmjF23.0330 & Hypothetical protein conserved & 120.0 & - \\
\hline
\end{tabular}

a: genes affected by anti-silencing protein 1 (ASF1) overexpression; ID: gene identification as annotated in the Leishmania major genome. 
son et al. 2005). It has been shown (Daganzo et al. 2003) that this core domain is sufficient to confer resistance to DNA damage agents and to guarantee interaction of ASF1 with its partners, $\mathrm{H} 3 / \mathrm{H} 4$ tetramer and Rad53. This conservation of the N-terminal region of LmASFl indicates that the hydrophobicity of this concave groove and its surrounding regions is maintained in L. major, which suggests that interaction of ASF1 with these partners is maintained in Leishmania.

We generated Leishmania parasites that produces higher amounts of ASF1 transcripts (90.5 times higher) and protein (at least 3 times higher) when compared to the control. The difference between ASF1 transcript and protein levels in the mutant is remarkable. This finding led us to speculate that this protein at high levels is deleterious to the parasite and that degradation of the excess of protein is necessary for the maintenance of cell homeostasis. Alternatively, the mRNA produced is degraded before being translated. These hypotheses are supported by other observations made in the course of this study. One of them is the fact that the ASF-overexpressing parasite presented a delayed growth, with a doubling time of $8.67 \mathrm{~h}$ compared to $6.84 \mathrm{~h}$ observed in the control line (Fig. 3A). Another possibility to explain the growth rate decrease is that cells have a delay in the $\mathrm{S}$ phase, a finding compatible with the fact that Asf1A is a substrate for Tousled-like kinases implicated in DNA replication control in T. brucei (Li et al. 2007). Nevertheless, we have not observed more than a subtle apparent increase on S-phase non synchronized cells, which was not confirmed in experimental triplicates (Fig. 3B).

ASF1 was originally identified as a disrupter of silencing of specific loci in S. cerevisiae (Le et al. 1997, Singer et al. 1998). In yeast, position-dependent gene silencing, including telomere silencing, involves many factors responsible for chromatin/nucleosome assembly, for instance ScAsflp (Sharp et al. 2001). The fact that telomere proximal domains are less accessible to the transcriptional machinery, as compared to other chromosome regions, offers protection to these regions (Gottschling 1992). In several organisms, including $T$. brucei, this is achieved by repression of nearby genes (Levis et al. 1985, Gottschling et al. 1990, Zomerdijk et al. 1991, Horn \& Cross 1995), with the control of chromatin packaging being essential for the strict control of the variant surface glycoproteins expression in these parasites (Rudenko 2010). To search for a potential role for $L m A S F 1$ over telomere-proximal genes transcriptional control, we quantified the transcript level of 42 genes of Leishmania, mostly from the telomere proximal domains. We found that the augmented levels of ASF1 did not change the expression levels of any of the telomere-proximal genes analyzed (Table I), suggesting that differently than $S$. cerevisiae's ASF1, the parasitic homologue is not involved in the expression control of telomeric genes. Nevertheless, we cannot rule out that a different factor plays this function in Leishmania.

Through proteomic analysis we investigated the potential changes that overexpression of ASF1 induced in gene expression. Interestingly, we observed changed levels of two proteins related to proteolytic activity (Table
II). These proteins are the ubiquitin conjugating enzyme (Lmj33.2770) and a metalloprotease (LmjF05.0960). In addition, there is a third protein that might be also involved in proteolysis; it is classified as an ATPase beta subunit protein (LmjF25.1170) that might be a member of the AAA ATPase family, which participates in a variety of cellular processes, including the shuttle of a subset of ubiquitinated substrates to the proteasome for degradation (Ye 2006). An indication that the ASF1 mutant was under stress comes from the overexpression of genes involved in physiological stress processes (LmjF11.0350, LmjF26.1240, LmjF30.2460, Lmj28.2770, LmjF36.2030, LmjF08.1110) (Table II, Supplementary data). Furthermore, the detection of altered levels of three proteins involved in the oxidoreductase activity (LmjF23.0040, LmjF23.0360, LmjF07.0430) suggests that cell redox metabolism is affected in the mutant.

Because ASF1 has a wide spectrum of functions related to chromatin metabolism, control of ASF1 levels must be critical for cell viability. ASF1 post-translational modifications were shown to be relevant for the control of its own cellular levels. It has been shown that phosphorylation of human and Drosophila ASF1 by tousled-like kinases (TLK) positively regulates protein levels, because it hampers the proteasome-dependent degradation of ASF1 (Pilyugin et al. 2009). In T. brucei, both ASF1 isoforms interact and are phosphorylated by TLK1 (Li et al. 2007). Currently, we have no information on the occurrence of post-translational modifications of LmASF1, nor whether or not it interacts with the L. major TLK. Assuming that the post-translational process happens similarly to that in T. brucei, we speculate that the endogenous LmTLK is unable to phosphorylate the excess of ASF1 produced by the mutant and that the unstable ASF1 is ubiquinated and shuttled to the proteasome to recover the organism homeostasis.

Finally, consistent with the LmASF1 role in the control of chromatin dynamics, which interacts with other CAFs, we found in the comparative proteomic analysis (Table II, Supplementary data) that two of the proteins found in higher levels in the ASF1 mutant are involved in chromatin remodelling (LmjF29.2340 and LmjF19.0440). Interaction of these proteins with ASF1 must be further investigated.

It has been shown that in other organisms ASF1 contribution to DNA repair is also linked to its effect on assembly/disassembly of chromatin, which is similar to what has been shown for its DNA replication or control of transcription (Mello et al. 2002, Gontijo et al. 2003, Green \& Almouzni 2003, Canfield et al. 2009). The remarkable decrease in multiplication rates of ASF1 mutant in the presence of MMS indicates that this $L m A S F 1$ isoform modifies the response to DNA damage. It is possible that high levels of ASF1 affect the chromatin structure, making the overexpressor's DNA more susceptible to the genotoxic effect of MMS. Alternatively, the delayed growth rate of the ASF1 overexpressor may be the result of the parasite attempt to maintain cellular homeostasis combined to the deleterious effects of the genotoxic agent. 


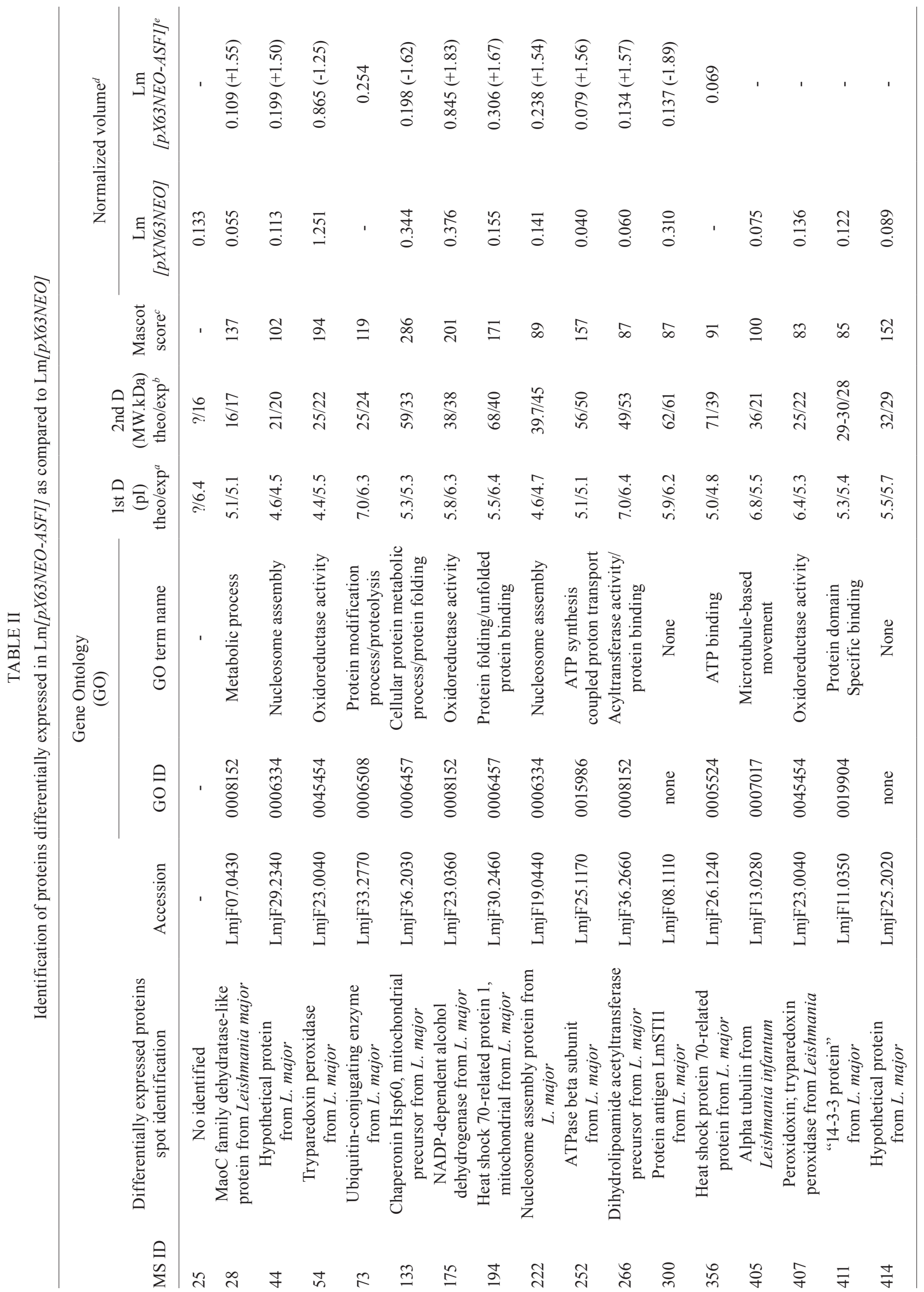




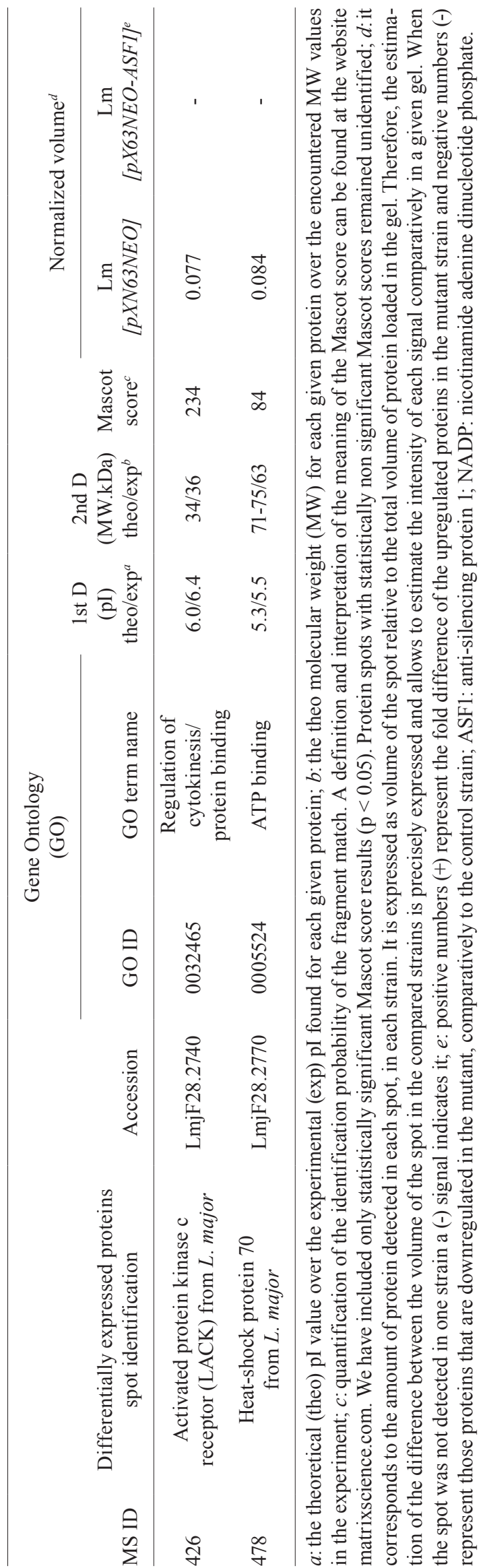

Overall, our results indicate that the Leishmania ASF1 is not involved in controlling the expression of telomeric genes. On the other hand, altered levels of nucleosome assembly proteins (putative partners of ASF1) and the delayed growth rate of ASF1 overexpressor when submitted to a clastogenic agent indicate that ASF1 is involved in chromatin assembly/disassembly. Changed levels of proteins potentially involved in physiological stress conditions and in proteolytic processes, combined with the observed impaired growth rates, indicate that overexpression of ASF1 is deleterious to the parasite. Chromatin assembly dynamics is relevant for controlling transcription in trypanosomatids (Green \& Almouzni 2003, Figueiredo et al. 2009) and is central for the DNA repair machinery. Investigating the roles and interactions of Leishmania's ASF1 is a route to improve understanding of how this important biological process may occur in trypanosomatids.

\section{ACKNOWLEDGEMENTS}

To Tânia PA Defina and Viviane A Trombela, for technical assistance.

\section{REFERENCES}

Adkins MW, Williams SK, Linger J, Tyler JK 2007. Chromatin disassembly from the PHO5 promoter is essential for the recruitment of the general transcription machinery and coactivators. Mol Cell Biol 27: 6372-6382.

Bradford MM 1976. A rapid and sensitive method for the quantitation of microgram quantities of protein utilizing the principle of protein-dye binding. Anal Biochem 72: 248-254.

Canfield C, Rains J, De Benedetti A 2009. TLK1B promotes repair of DSBs via its interaction with Rad9 and Asf1. BMC Mol Biol 10: 110 .

Clayton CE 2002. Life without transcriptional control? From fly to man and back again. Embo J 21: 1881-1888.

Daganzo SM, Erzberger JP, Lam WM, Skordalakes E, Zhang R, Franco AA, Brill SJ, Adams PD, Berger JM, Kaufman PD 2003. Structure and function of the conserved core of histone deposition protein Asf1. Curr Biol 13: 2148-2158.

Elias MC, Marques-Porto R, Freymuller E, Schenkman S 2001. Transcription rate modulation through the Trypanosoma cruzi life cycle occurs in parallel with changes in nuclear organisation. Mol Biochem Parasitol 112: 79-90.

Emili A, Schieltz DM, Yates JR 3rd, Hartwell LH 2001. Dynamic interaction of DNA damage checkpoint protein Rad53 with chromatin assembly factor Asf1. Mol Cell 7: 13-20.

Feinberg AP, Vogelstein B 1983. A technique for radiolabelling DNA restriction endonuclease fragments to high specific activity. Anal Biochem 132: 6-13.

Figueiredo LM, Cross GA, Janzen CJ 2009. Epigenetic regulation in African trypanosomes: a new kid on the block. Nat Rev Microbiol 7: 504-513.

Gontijo AM, Green CM, Almouzni G 2003. Repairing DNA damage in chromatin. Biochimie 85: 1133-1147.

Gottschling DE 1992. Telomere-proximal DNA in Saccharomyces cerevisiae is refractory to methyltransferase activity in vivo. Proc Natl Acad Sci USA 89: 4062-4065.

Gottschling DE, Aparicio OM, Billington BL, Zakian VA 1990. Position effect at $S$. cerevisiae telomeres: reversible repression of Pol II transcription. Cell 63: 751-762. 
Green CM, Almouzni G 2003. Local action of the chromatin assembly factor CAF-1 at sites of nucleotide excision repair in vivo. Embo J 22: 5163-5174.

Horn D, Cross GA 1995. A developmentally regulated position effect at a telomeric locus in Trypanosoma brucei. Cell 83: 555-561.

Hu F, Alcasabas AA, Elledge SJ 2001. Asf1 links Rad53 to control of chromatin assembly. Genes Dev 15: 1061-1066.

Kapler GM, Coburn CM, Beverley SM 1990. Stable transfection of the human parasite Leishmania major delineates a 30-kilobase region sufficient for extrachromosomal replication and expression. Mol Cell Biol 10: 1084-1094.

Le S, Davis C, Konopka JB, Sternglanz R 1997. Two new S-phase-specific genes from Saccharomyces cerevisiae. Yeast 13: 1029-1042.

LeBowitz JH, Coburn CM, Beverley SM 1991. Simultaneous transient expression assays of the trypanosomatid parasite Leishmania using $\beta$-galactosidase and $\beta$-glucoronidase as reporter enzymes. Gene 103: 119-123.

Levis R, Hazelrigg T, Rubin GM 1985. Separable cis-acting control elements for expression of the white gene of Drosophila. Embo $J$ 4: 3489-3499.

Li Z, Gourguechon S, Wang CC 2007. Tousled-like kinase in a microbial eukaryote regulates spindle assembly and S-phase progression by interacting with Aurora kinase and chromatin assembly factors. J Cell Sci 120: 3883-3894.

Loyola A, Almouzni G 2004. Histone chaperones, a supporting role in the limelight. Biochim Biophys Acta 1677: 3-11.

Martinez-Calvillo S, Vizuet-de-Rueda JC, Florencio-Martinez LE, Manning-Cela RG, Figueroa-Angulo EE 2010. Gene expression in trypanosomatid parasites. J Biomed Biotechnol: e525241.

McNairn AJ, Gilbert DM 2003. Epigenomic replication: linking epigenetics to DNA replication. Bioessays 25: 647-656.

Mello JA, Sillje HH, Roche DM, Kirschner DB, Nigg EA, Almouzni G 2002. Human Asf1 and CAF-1 interact and synergize in a repaircoupled nucleosome assembly pathway. EMBO Rep 3: 329-334.

Mousson F, Lautrette A, Thuret JY, Agez M, Courbeyrette R, Amigues B, Becker E, Neumann JM, Guerois R, Mann C, Ochsenbein F 2005. Structural basis for the interaction of Asf1 with histone $\mathrm{H} 3$ and its functional implications. Proc Natl Acad Sci USA 102: 5975-5980.

Navarro M, Cross GA, Wirtz E 1999. Trypanosoma brucei variant surface glycoprotein regulation involves coupled activation/inactivation and chromatin remodelling of expression sites. Embo $J$ 18: $2265-2272$

Neuhoff V, Arold N, Taube D, Ehrhardt W 1988. Improved staining of proteins in polyacrylamide gels including isoelectric focusing gels with clear background at nanogram sensitivity using Coomassie Brilliant Blue G-250 and R-250. Electrophoresis 9: 255-262.

Pedrosa AL, Ruiz JC, Tosi LRO, Cruz AK 2001. Characterisation of three chromosomal ends of Leishmania major reveals transcriptional activity across arrays of reiterated and unique sequences Mol Biochem Parasitol 114: 71-80.

Pilyugin M, Demmers J, Verrijzer CP, Karch F, Moshkin YM 2009. Phosphorylation-mediated control of histone chaperone ASF1 levels by Tousled-like kinases. PLoS ONE 4: e8328.
Prado F, Cortes-Ledesma F, Aguilera A 2004. The absence of the yeast chromatin assembly factor Asf1 increases genomic instability and sister chromatid exchange. EMBO Rep 5: 497-502.

Rudenko G 2010. Epigenetics and transcriptional control in African trypanosomes. Essays Biochem 48: 201-219.

Sanematsu F, Takami Y, Barman HK, Fukagawa T, Ono T, Shibahara K, Nakayama T 2006. Asf1 is required for viability and chromatin assembly during DNA replication in vertebrate cells. J Biol Chem 281: 13817-13827.

Schwabish MA, Struhl K 2006. Asf1 mediates histone eviction and deposition during elongation by RNA polymerase II. Mol Cell 22: 415-422.

Shapiro SZ, Naessens J, Liesegang B, Moloo SK, Magondu J 1984. Analysis by flow cytometry of DNA synthesis during the life cycle of African trypanosomes. Acta Trop 41: 313-323.

Sharp JA, Fouts ET, Krawitz DC, Kaufman PD 2001. Yeast histone deposition protein Asf1p requires Hir proteins and PCNA for heterochromatic silencing. Curr Biol 11: 463-473.

Singer MS, Kahana A, Wolf AJ, Meisinger LL, Peterson SE, Goggin C, Mahowald M, Gottschling DE 1998. Identification of highcopy disruptors of telomeric silencing in Saccharomyces cerevisiae. Genetics 150: 613-632.

Sutton A, Bucaria J, Osley MA, Sternglanz R 2001. Yeast ASF1 protein is required for cell cycle regulation of histone gene transcription. Genetics 158: 587-596.

Takahata S, Yu Y, Stillman DJ 2009. FACT and Asf1 regulate nucleosome dynamics and coactivator binding at the $\mathrm{HO}$ promoter. Mol Cell 34: 405-415.

Tamburini BA, Carson JJ, Adkins MW, Tyler JK 2005. Functional conservation and specialization among eukaryotic anti-silencing function 1 histone chaperones. Eukaryot Cell 4: 1583-1590.

Tyler JK, Adams CR, Chen SR, Kobayashi R, Kamakaka RT, Kadonaga JT 1999. The RCAF complex mediates chromatin assembly during DNA replication and repair. Nature 402: 555-560.

Tyler JK, Collins KA, Prasad-Sinha J, Amiott E, Bulger M, Harte PJ, Kobayashi R, Kadonaga JT 2001. Interaction between the Drosophila CAF-1 and ASF1 chromatin assembly factors. Mol Cell Biol 21: 6574-6584.

Varv S, Kristjuhan K, Peil K, Looke M, Mahlakoiv T, Paapsi K, Kristjuhan A 2010. Acetylation of H3 K56 is required for RNA polymerase II transcript elongation through heterochromatin in yeast. Mol Cell Biol 30: 1467-1477.

Ye Y 2006. Diverse functions with a common regulator: ubiquitin takes command of an AAA ATPase. J Struct Biol 156: 29-40.

Zhang R, Poustovoitov MV, Ye X, Santos HA, Chen W, Daganzo SM, Erzberger JP, Serebriiskii IG, Canutescu AA, Dunbrack RL, Pehrson JR, Berger JM, Kaufman PD, Adams PD 2005. Formation of macroH2A-containing senescence-associated heterochromatin foci and senescence driven by ASF1a and HIRA. Dev Cell 8: 19-30.

Zomerdijk JC, Kieft R, Duyndam M, Shiels PG, Borst P 1991. Antigenic variation in Trypanosoma brucei: a telomeric expression site for variant-specific surface glycoprotein genes with novel features. Nucleic Acids Res 19: 1359-1368. 
Lm[pX63NEO]

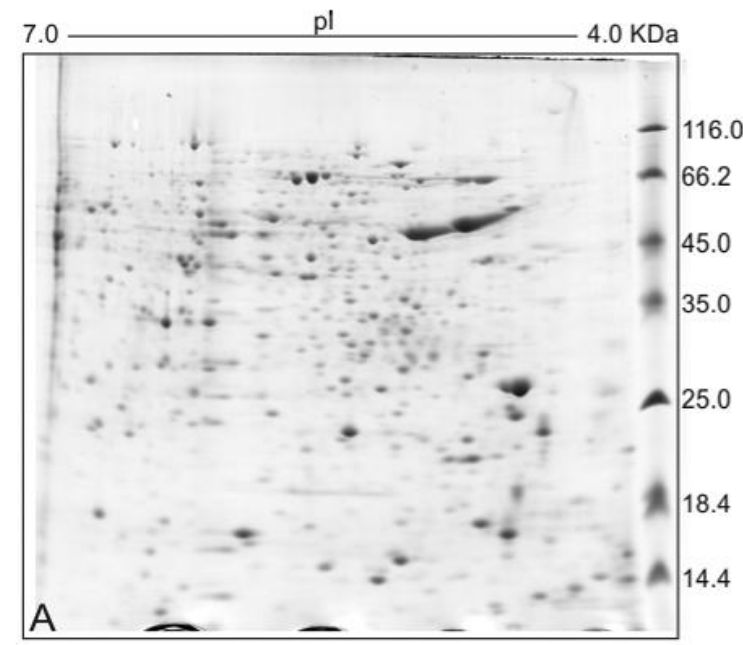

Lm[pX63NEO-ASF1]

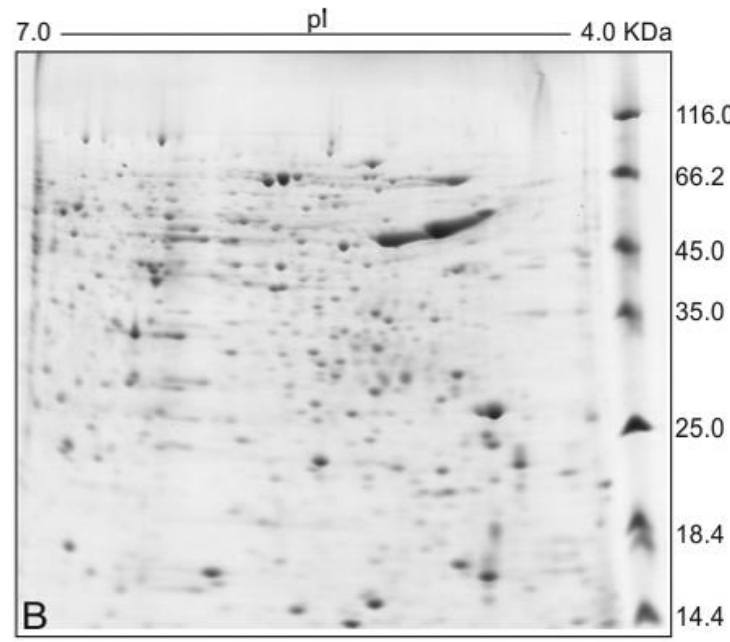

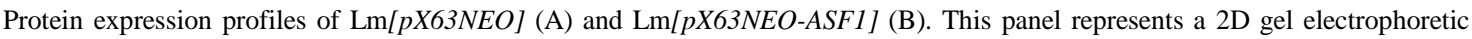
fractionation of proteins from each cell lines of the three independent experiments. Equal amounts $(700 \mu \mathrm{g})$ of proteins were fractionated on the $13 \mathrm{~cm}$ pI 4-7 linear gradient focused $\mathrm{pH}$ gradient strips and by $12 \%$ sodium dodecyl sulfate polyacrylamide gel electrophoresis. 
Supplementary data

List of genes and primers used in the quantitative real-time polymerase chain reaction

\begin{tabular}{|c|c|c|}
\hline Oligonucleotide ID ${ }^{a}$ & Gene ID & Sequence \\
\hline LmjF01.0010 (R) & LmjF01.0010 & ATGGGAACGTTTCGTTGCACTTCG \\
\hline LmjF01.0010 (F) & LmjF01.0010 & CACACGTACAAGTACTGCGGCAAA \\
\hline LmjF01.0020 (R) & LmjF01.0020 & GTTGTACGTGATGCCTTTCGCCTT \\
\hline LmjF01.0020 (F) & LmjF01.0020 & GGCTCACAAGAAGCAACAACAGCA \\
\hline LmjF01.0810 (R) & LmjF01.0810 & TCGTGGCGAAGGCGACGATAATAA \\
\hline LmjF01.0810 (F) & LmjF01.0810 & TGGTCCGCTACTTTATTCGGCTGT \\
\hline LmjF01.0820 (R) & LmjF01.0820 & AGTAGCTGAAGCCGACACCAATGA \\
\hline LmjF01.0820 (F) & LmjF01.0820 & ACATGATGCTGCTGTCCTTCTCGT \\
\hline $\mathrm{SCG} 3(\mathrm{~F})$ & LmjF02.0010 & GCGCGTGTGCTACATGGC \\
\hline $\operatorname{SCG} 3(R)$ & LmjF02.0010 & AGAATCTGGTGCGCCCGG \\
\hline LmjF02-SCA (F) & LmjF02.0180 & CACCACTGCTGTGCCATACT \\
\hline LmjF02-SCA (R) & LmjF02.0180 & TATGTTGGTGCTCGTCTCGT \\
\hline LmjF02.0190 (F) & LmjF02.0190 & TAGGCCAGGATGAAGACACCG \\
\hline LmjF02.0190 (R) & LmjF02.0190 & CGCGGTGAAGGCTGGAAT \\
\hline LbrM03-0090 (F) & LmjF03.0080 & ATCGGTGGCATTATCAA \\
\hline LbrM03.0090 (R) & LmjF03.0080 & GAGTAGAGGAAGACGATGAACG \\
\hline LmjF04.0010 (F) & LmjF04.0010 & TCGACAAACAAGTGGCTCATTGCG \\
\hline LmjF04.0010 (R) & LmjF04.0010 & AGTCCGTGAAATCAGTAGGCAGCA \\
\hline LbrM04.0040 (F) & LmjF04.0020 & AGGGGTGTGAGAGCACGATGT \\
\hline LbrM04.0040 (R) & LmjF04.0020 & AGGTTGCTGAAGTCGCAC \\
\hline LmjF04.0030 (F) & LmjF04.0030 & ATTTGCAGAGCTCAACGTCATCGC \\
\hline LmjF04.0030 (R) & LmjF04.0030 & TGTGTAGCGAGGCGAAGAAGGAAA \\
\hline LmjF04.0060 (F) & LmjF04.0060 & ACTCAACCGCGAGGAGAACATCAT \\
\hline LmjF04.0060 (R) & LmjF04.0060 & TCTTCTGGATGGTTGCGGAGAAGA \\
\hline LmjF04.1160 (F) & LmjF04.1160 & TGGCGACTTCACGCTCTTGATGAT \\
\hline LmjF04.1160 (R) & LmjF04.1160 & AGATCACATCCAGCTTCGCCTGAT \\
\hline LmjF04.1190 (F) & LmjF04.1190 & AATACAGCAGGCTACGAGCGACTT \\
\hline LmjF04.1190 (R) & LmjF04.1190 & AGCAGCGTTGTTCCAACGTTCTTG \\
\hline LmjF04.1220 (F) & LmjF04.1220 & ACTCTTTAGTGAACACGCTGGCGA \\
\hline LmjF04.1220 (R) & LmjF04.1220 & AGTGCTTGGGAGACGTAAGCTTCT \\
\hline LbrM08-0080 (F) & LmjF08.0080 & TGGGCTACGCAAACCGC \\
\hline LbrM08-0080 (R) & LmjF08.0080 & ATATCCAAACCGCGCTCTGC \\
\hline LbrM09.0090 (F) & LmjF09.0070 & TCGCACTGAGGTGGAGAATA \\
\hline LbrM09.0090 (R) & LmjF09.0070 & AGTGTGGCAGGTGACAAGTA \\
\hline LmjF11.0010 (F) & LmjF11.0010 & TGGCTGCTGCGAATAATCTCCTGA \\
\hline $\mathrm{LmjF} 11.0010(\mathrm{R})$ & LmjF11.0010 & GAGCATCTGCGAAAGCGGATTTGT \\
\hline LmjF11.0020 (F) & LmjF11.0020 & AGATGTTTCCCTCGACAAAGGGCT \\
\hline LmjF11.0020 (R) & LmjF11.0020 & AGACGATTGCAAGGCATAAACGGG \\
\hline $\mathrm{LmjF} 11.0030(\mathrm{~F})$ & LmjF11.0030 & AGGCGATAGTCACGGGAAACACAA \\
\hline LmjF11.0030 (R) & LmjF11.0030 & AAACGAGCACGACGCAATATCAGC \\
\hline $\operatorname{LmjF} 11.1360(\mathrm{~F})$ & $\mathrm{LmjF} 11.1360$ & TCGCGAGTTGGACCCGTTCATATT \\
\hline $\operatorname{LmjF} 11.1360(\mathrm{R})$ & $\mathrm{LmjF} 11.1360$ & CCAATTCTTCTTGGCCTTTCGCCA \\
\hline LmjF11.1370 (F) & LmjF11.1370 & ACCTCAGCTCGAACGGCTTTATCA \\
\hline LmjF11.1370 (R) & LmjF11.1370 & GAAAGCAAAGGCAGCCATGTCGAA \\
\hline LmjF11.1380 (F) & LmjF11.1380 & ACAAGAGAGCAGTACCGACAGCTT \\
\hline LmjF11.1380 (R) & LmjF11.1380 & TAACGGCGTTGCCTTTCTTGATGC \\
\hline
\end{tabular}




\begin{tabular}{|c|c|c|}
\hline LmjF18.0010 (F) & LmjF18.0010 & AGATGCCACTCTCTGCTGAACTGT \\
\hline LmjF18.0010 (R) & LmjF18.0010 & TGACGATAGAGTCACACGTTGCGT \\
\hline LmjF18.0020 (F) & $\mathrm{LmjF} 18.0020$ & CGCGAATTGCTTCATGTTCACCCT \\
\hline LmjF18.0020 (R) & LmjF18.0020 & TGCACTTCTCCAAGAGGTCTGCAT \\
\hline LmjF18.0030 (F) & $\mathrm{LmjF} 18.0030$ & TGCAGCGGTTGTGTACATCTTCCT \\
\hline LmjF18.0030 (R) & $\mathrm{LmjF} 18.0030$ & GTAGCCACGTCGAATTGCAGCTTT \\
\hline LmjF18.1660 (F) & LmjF18.1660 & GTGACGATGCAGCTGGACAACATT \\
\hline LmjF18.1660 (R) & $\mathrm{LmjF} 18.1660$ & TGTCGCAAAGAAGACCCTTCTGGA \\
\hline LmjF18.1670 (F) & $\mathrm{LmjF} 18.1670$ & TGTCGCAAAGAAGACCCTTCTGGA \\
\hline LmjF18.1670 (R) & LmjF18.1670 & ATTTGATGGCTGTCCTCTGGGACT \\
\hline LmjF20.0020 (F) & $\mathrm{LmjF} 20.0020$ & TGTTTCTTGCGCGAGATGGTATGC \\
\hline LmjF20.0020 (R) & $\mathrm{LmjF} 20.0020$ & TGATGGGAGAGTAAGCCAAAGCGT \\
\hline LmjF20.0030 (F) & $\mathrm{LmjF} 20.0030$ & ACCCATCTTCGAGGCACAGTTCAA \\
\hline LmjF20.0030 (R) & $\mathrm{LmjF} 20.0030$ & ACGGCGTAGGAAAGTACACAGCA \\
\hline LmjF20.0040 (F) & $\mathrm{LmjF} 20.0040$ & CAGCAAAGAGAGCAACTGGCTTGT \\
\hline LmjF20.0040 (R) & $\mathrm{LmjF} 20.0040$ & TTGGGCAAACCAGCACTGTCAAAG \\
\hline LmjF20.0050 (F) & $\mathrm{LmjF} 20.0050$ & AAACTGTGTCCGTCTCCTTCGTGT \\
\hline LmjF20.0050 (R) & $\mathrm{LmjF} 20.0050$ & AGGTGAACTCAGTGATGCCCTTCT \\
\hline LmjF20.0060 (F) & $\mathrm{LmjF} 20.0060$ & TCATGCAGATGTACAACGCGGAGA \\
\hline LmjF20.0060 (R) & LmjF20.0060 & AGAGCTCATGTACAGCACCACCAA \\
\hline LmjF20.0070 (F) & $\mathrm{LmjF} 20.0070$ & TGACTTCTTCGAGACGCACCATGA \\
\hline LmjF20.0070 (R) & $\mathrm{LmjF} 20.0070$ & CAGCACACCAATGAGAAAGGCAGT \\
\hline LmjF20.0080 (F) & LmjF20.0080 & AGATAACACCGCGGGAGATGAAGT \\
\hline LmjF20.0080 (R) & $\mathrm{LmjF} 20.0080$ & AGCGGATTTGTTTCTTTCGACGCC \\
\hline LmjF20.0090 (F) & $\mathrm{LmjF} 20.0090$ & ACACTCGCCTTTATGATGGGTCGT \\
\hline LmjF20.0090 (R) & $\mathrm{LmjF} 20.0090$ & AGCTTGAAGAGCGTCTGTGACTGT \\
\hline LmjF20.1620 (F) & $\mathrm{LmjF} 20.1620$ & AGTGGTCTTGTAATCAGGCTGCGA \\
\hline LmjF20.1620 (R) & LmjF20.1620 & TGGTACACTTCAGCTCGCCTTCAT \\
\hline LbrM22.1580 (F) & $\mathrm{LmjF} 22.1670$ & AGGATAGGATGGCGGAGATT \\
\hline LbrM22.1580 (R) & LmjF22.1670 & TCAAGTTGTTGGGCGAGAAG \\
\hline LmjF23.0290 (F) & $\mathrm{LmjF} 23.0290$ & AACTGAAGAACACGGCAGCCGATA \\
\hline LmjF23.0290 (R) & $\mathrm{LmjF} 23.0290$ & TGAAGTGCTCGGCGTAGATGAGAA \\
\hline LmjF23.0300 (F) & $\mathrm{LmjF} 23.0300$ & AGCTGATTCGCAGCAACATCAAGG \\
\hline LmjF23.0030 (R) & $\mathrm{LmjF} 23.0300$ & CAAGCTTGCCGACATTATCGCTGT \\
\hline LmjF23.0310 (F) & $\mathrm{LmjF} 23.0310$ & CAATCGCGATCTTCAGCAGCACAA \\
\hline LmjF23.0310 (R) & $\mathrm{LmjF} 23.0310$ & AGCGTACAAGATGCGAGCCATAGT \\
\hline LmjF23.0320 (F) & $\mathrm{LmjF} 23.0320$ & TGCTGCGTACAAGTCCGACACTAA \\
\hline LmjF23.0320 (R) & $\mathrm{LmjF} 23.0320$ & TCACCGTCTTTGCTGTCGCTGTAA \\
\hline LT 197 & $\mathrm{LmjF} 23.0330$ & AGGTGGTTGTTGGCTTCCAAC \\
\hline LT 198 & LmjF23.0330 & AACAAACGACATGGCGAAGACCAC \\
\hline Lm G6PDH (F) & LmjF34.0080 & ACCGCATTGACCACTACCTC \\
\hline Lm G6PDH (R) & $\mathrm{LmjF} 34.0080$ & GATGTTGTTCGAGTTCCAC \\
\hline
\end{tabular}

$a$ : some primers were designed to amplify the corresponding gene fragment from the Leishmania braziliensis. ID: ?; R: reverse; F: forward. 
Supplementary data

Mass spectrometry of spots obtained from 2D gels. Identification of the proteins are presented in Table II

Sample: 25

Mass Spectrum (positive reflector)

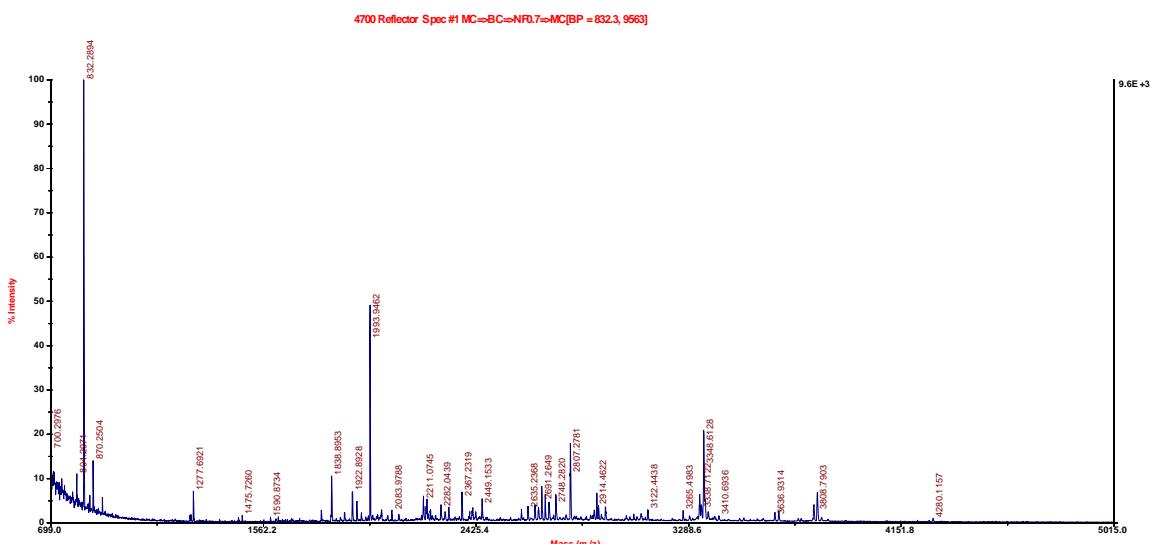

\section{Conclusion:}

- The spectrum shows only $\mathrm{m} / \mathrm{z}$ values corresponding to keratin tryptic peptides and trypsin autolytic fragments.

- With this data could not identify in a significant manner any protein in sample 25. 
Sample: 28

Mass Spectrum (positive reflector)

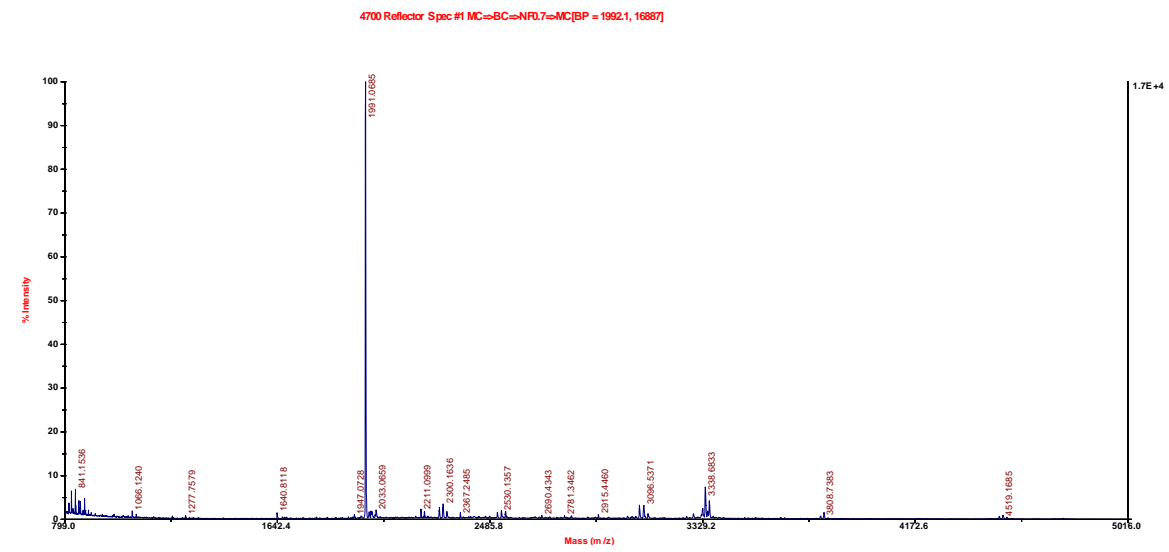

\section{Mascot Score Histogram}

Protein score is $-10 * \log (\mathrm{P})$, where $\mathrm{P}$ is the probability that the observed match is a random event. Protein scores greater than 83 are significant $(\mathrm{p}<0.05)$. Protein scores are derived from ions scores as a non-probabilistic basis for ranking protein hits.

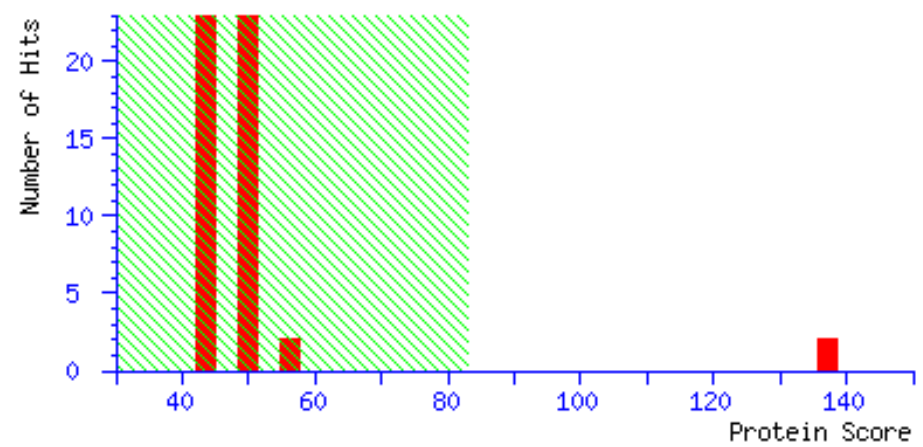

Match to: gi|157864476 Score: 137 Expect: 2.2e-07 maoc family dehydratase-like protein [Leishmania major] Nominal mass $\left(\mathrm{M}_{\mathrm{r}}\right)$ : 16974; Calculated pI value: 5.14 NCBI BLAST search of gi|157864476 against nr Unformatted sequence string for pasting into other applications Taxonomy: Leishmania major strain Friedlin Links to retrieve other entries containing this sequence from NCBI Entrez: gi|68124241 from Leishmania major strain Friedlin Variable modifications: Carbamidomethyl (C),Oxidation (M) Cleavage by Trypsin: cuts C-term side of KR unless next residue is P Sequence Coverage: $\mathbf{3 5 \%}$

Matched peptides shown in Bold:

1 MSSETAPLVI RVGSRATRTV HISQENVNTF GDVIDDHNPI HSDPEAARAA 51 GFPTTICYGM YAGSLFSGLM AKEMPGPGTV YLSQNLRFTA PVFVGDDLDV 101 IVEVREFRKD KGLISLSNIV QKTDPSTGKT TVCVEGSAVV MNKTLQFEGE 151 SEWSVTK 
Sample: 44

Mass Spectrum (positive reflector)

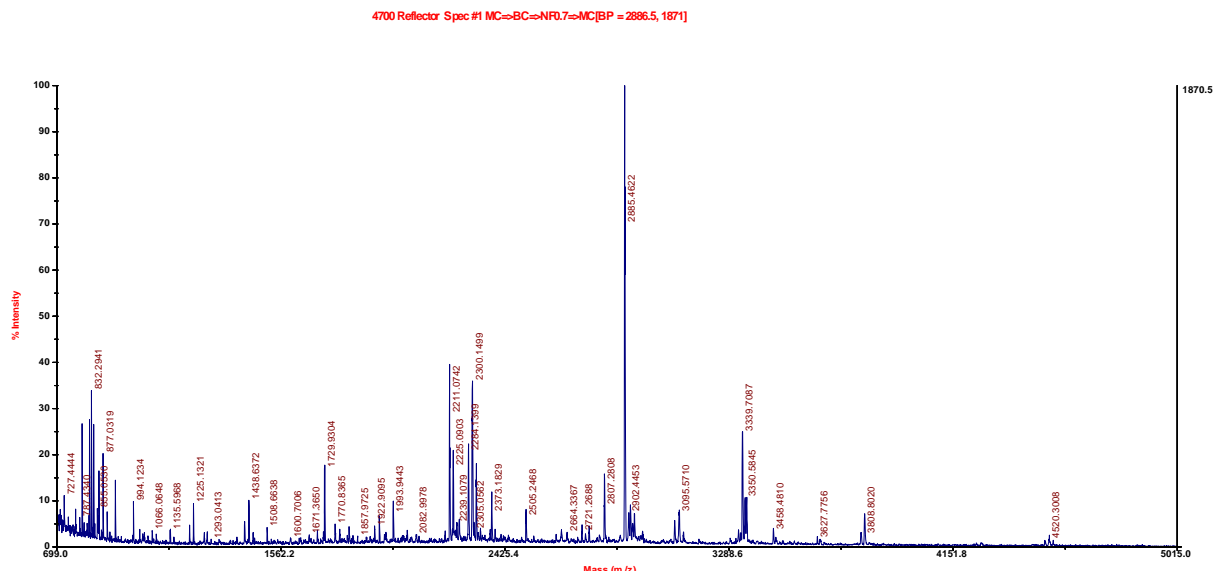

Mascot Score Histogram

Protein score is $-10 * \log (\mathrm{P})$, where $\mathrm{P}$ is the probability that the observed match is a random event. Protein scores greater than 83 are significant $(\mathrm{p}<0.05)$. Protein scores are derived from ions scores as a non-probabilistic basis for ranking protein hits.

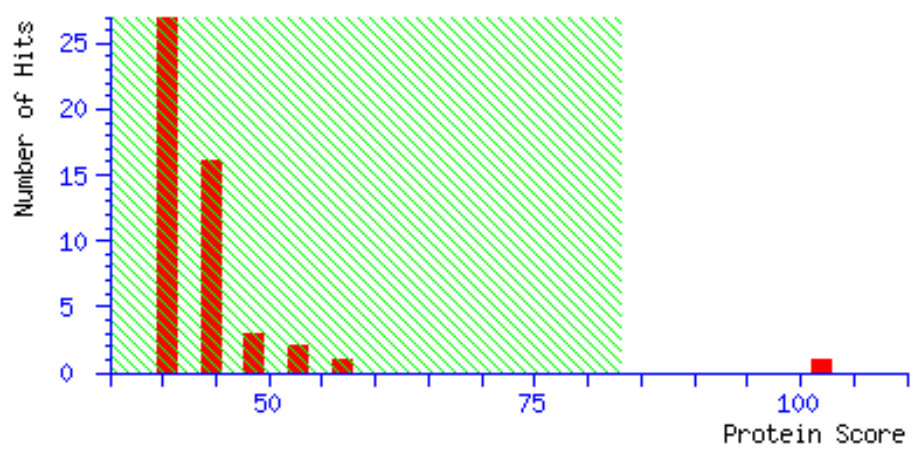

Match to: gi|73536961 Score: 102 Expect: 0.0007 hypothetical protein [Leishmania major strain Friedlin] Nominal mass $\left(\mathrm{M}_{\mathrm{r}}\right)$ : 21157; Calculated pI value: 4.61 NCBI BLAST search of gi|73536961 against nr Unformatted sequence string for pasting into other applications Taxonomy: Leishmania major strain Friedlin Links to retrieve other entries containing this sequence from NCBI Entrez: gi|70799775 from Leishmania major strain Friedlin Variable modifications: Oxidation (M) Cleavage by Trypsin: cuts C-term side of KR unless next residue is P Sequence Coverage: $\mathbf{4 0 \%}$ Matched peptides shown in Bold:

1 MELSQCATQA ISKFTDDLES IDRKCEEETT ALRLEYRSKM EPLLMERREL 51 LKGVTNFWSG VLSSPETPIA ALLNGTIDPK IIRAVTDFQV VTRISENKLY 101 RKIIFTFRQN MFVEEGEISR EVDTDMETTS LHPVKWKSGT ERARTDSFFA 151 FFTENFSSDP EDVMEVTEAL DTIYQNPFLA VEAD 


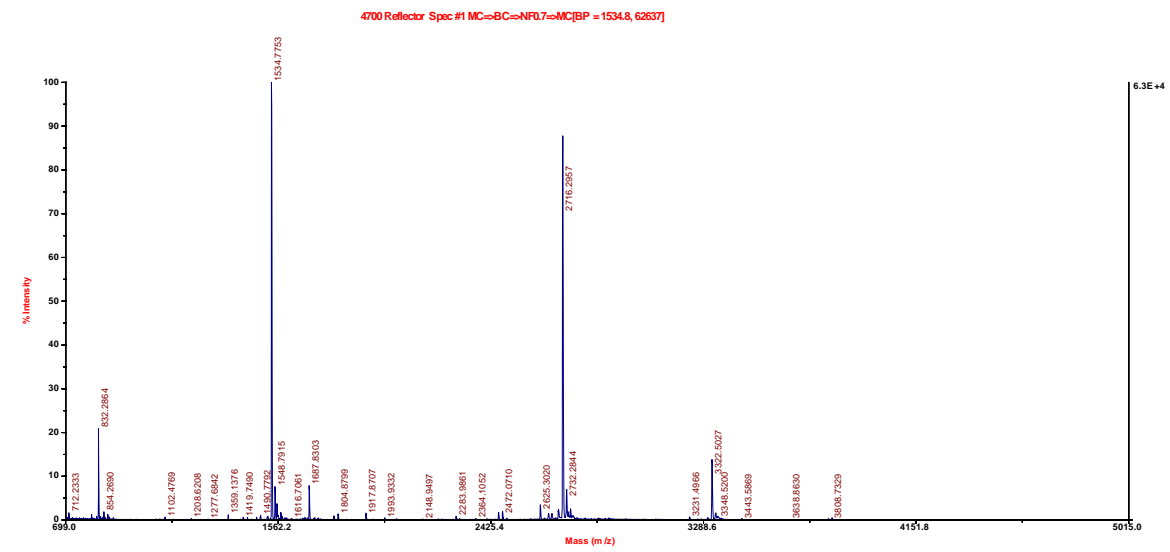

\section{Mascot Score Histogram}

Protein score is $-10 * \log (\mathrm{P})$, where $\mathrm{P}$ is the probability that the observed match is a random event. Protein scores greater than 83 are significant $(\mathrm{p}<0.05)$. Protein scores are derived from ions scores as a non-probabilistic basis for ranking protein hits.

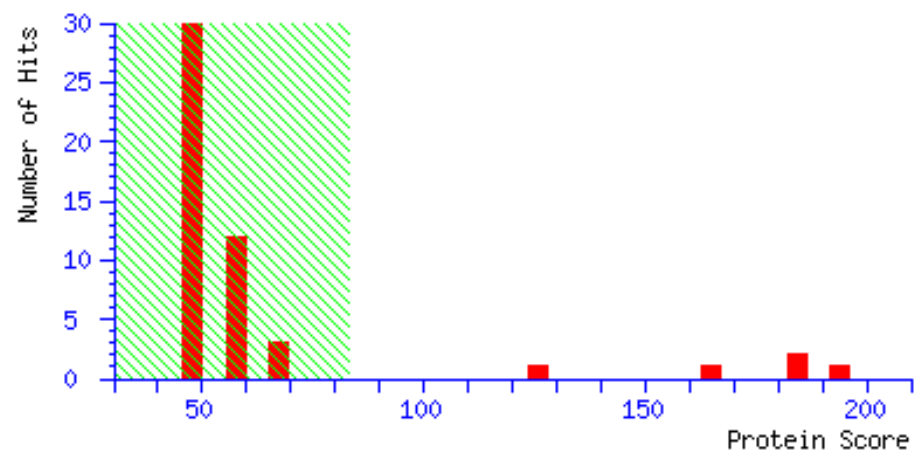

Match to: gi|157869550 Score: 194 Expect: 4.4e-13 peroxidoxin; tryparedoxin peroxidase [Leishmania major] Nominal mass $\left(\mathrm{M}_{\mathrm{r}}\right)$ : 25326; Calculated $\mathrm{pI}$ value: 6.43 NCBI BLAST search of gi|157869550 against nr Unformatted sequence string for pasting into other applications Taxonomy: Leishmania major strain Friedlin Links to retrieve other entries containing this sequence from NCBI Entrez: gi|68126391 from Leishmania major strain Friedlin Variable modifications: Oxidation (M),Carbamidomethyl (C) Cleavage by Trypsin: cuts C-term side of KR unless next residue is P Sequence Coverage: $\mathbf{5 2 \%}$

Matched peptides shown in Bold:

1 MLRRLSTSSF LKRAQFRGFA ATSPLLNLDY QMYRTATVRE AAPQFSGQAV

51 VNGAIKDINM NDYKGKYIVL FFYPMDFTFV CPTEIIAFSD RHADFEKLNT

101 QVVAVSCDSV YSHLAWVNTP RKKGGLGEMH IPVLADKSME IARDYGVLIE

151 ESGIALRGLF IIDKKGILRH STINDLPVGR NVDEALRVLE AFQYADENGD

201 AIPCGWKPGQ PTLDTTKAAE FFEKNM 
Sample: 73

Mass Spectrum (positive reflector)

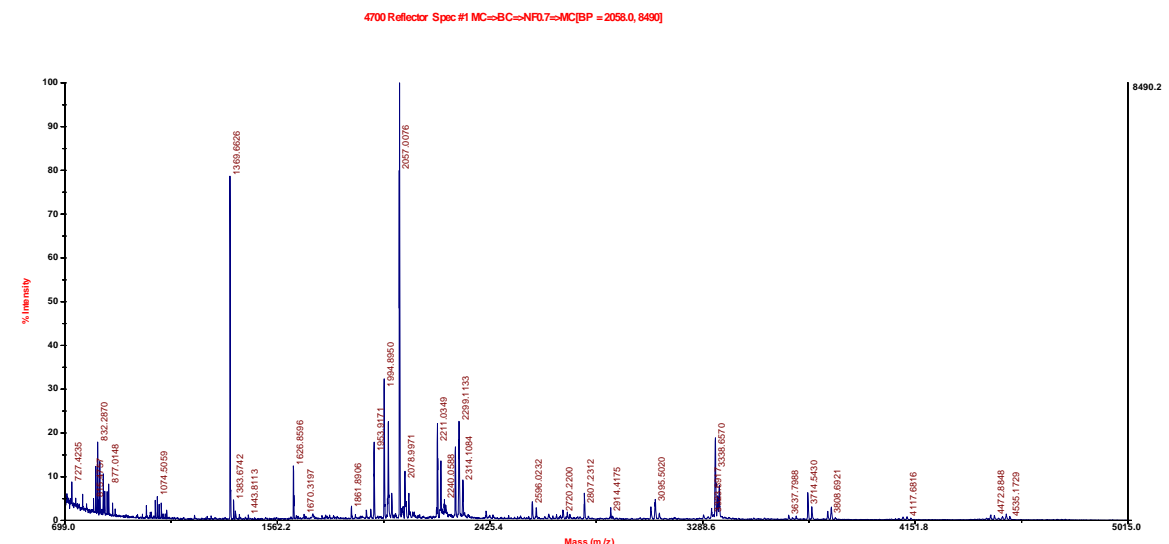

\section{Mascot Score Histogram}

Protein score is $-10 * \log (\mathrm{P})$, where $\mathrm{P}$ is the probability that the observed match is a random event. Protein scores greater than 83 are significant $(\mathrm{p}<0.05)$. Protein scores are derived from ions scores as a non-probabilistic basis for ranking protein hits.

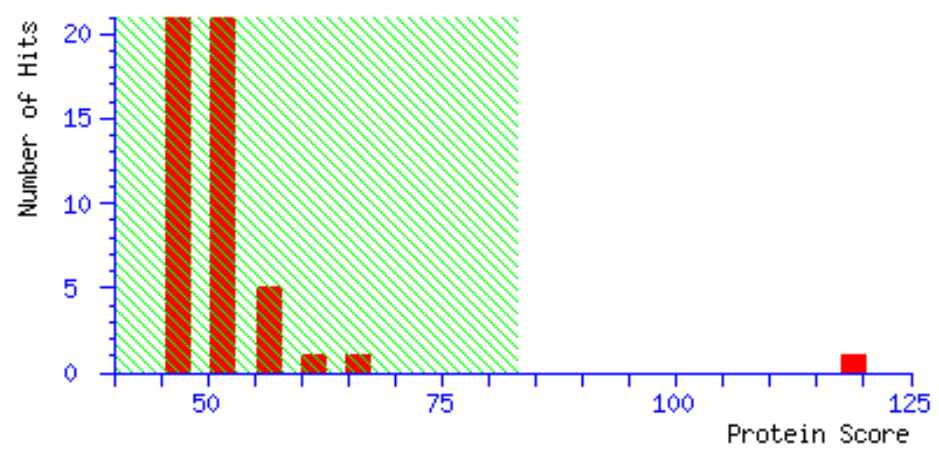

Match to: gi|157875282 Score: 119 Expect: 1.4e-05 ubiquitin-conjugating enzyme [Leishmania major strain Friedlin] Nominal mass $\left(M_{r}\right)$ : 25934; Calculated pI value: 7.01 NCBI BLAST search of gi|157875282 against nr Unformatted sequence string for pasting into other applications Taxonomy: Leishmania major strain Friedlin Links to retrieve other entries containing this sequence from NCBI Entrez: gi|68129113 from Leishmania major strain Friedlin Variable modifications: Oxidation (M),Carbamidomethyl (C) Cleavage by Trypsin: cuts C-term side of KR unless next residue is $\mathrm{P}$ Sequence Coverage: $\mathbf{2 2 \%}$

Matched peptides shown in Bold:

1 MPLTAAGMRT LMRQMQEVQE HPVDGVQVRP SDSMNEYHFD VDGPEGTPFA 51 AGRFHVVLIF DEQYPEVPPK GFFRTKIFHP NISERGDICV NTLKRDWSPM 101 LGLRHILVVI RCLLIEPNPE SALNEEAGRL ILEEYAAYER KAAMYTAINA 151 ARPNGVPRFT LPEVKAEKAS GSVTACASAG AAADSGASAT AAAAAASASS 201 MANGGAPSTA TRGLTLSEAN CHPGSATAAE KAEKSKKKAL RRI 
Sample: 133

Mass Spectrum (positive reflector)

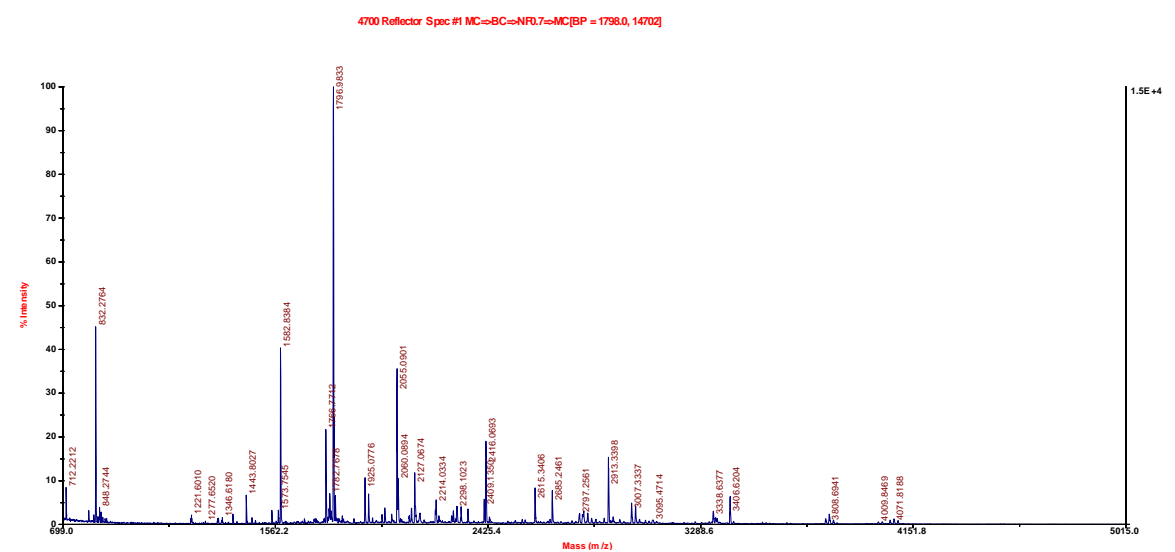

\section{Mascot Score Histogram}

Protein score is $-10 * \log (\mathrm{P})$, where $\mathrm{P}$ is the probability that the observed match is a random event. Protein scores greater than 83 are significant $(\mathrm{p}<0.05)$. Protein scores are derived from ions scores as a non-probabilistic basis for ranking protein hits.

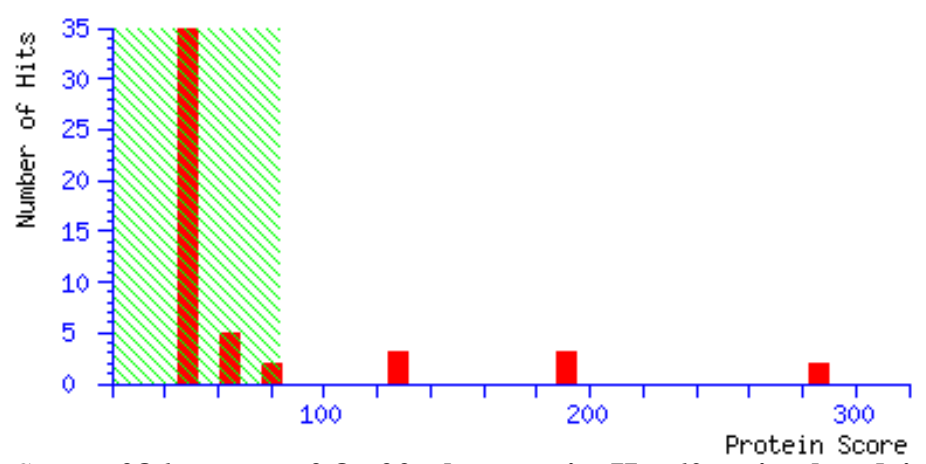

Match to: gi|157876872 Score: 286 Expect: 2.8e-22 chaperonin Hsp60, mitochondrial precursor [Leishmania major] Nominal mass $\left(\mathrm{M}_{\mathrm{r}}\right)$ : 59281; Calculated pI value: 5.33 NCBI BLAST search of gi|157876872 against nr Unformatted sequence string for pasting into other applications Taxonomy: Leishmania major strain Friedlin Links to retrieve other entries containing this sequence from NCBI Entrez:gi|68129853 from Leishmania major strain Friedlin Variable modifications: Oxidation (M),Carbamidomethyl (C) Cleavage by Trypsin: cuts C-term side of KR unless next residue is P Sequence Coverage: $\mathbf{2 4 \%}$

Matched peptides shown in Bold :

1 MLRSAVCLAG KDVRFSDKAR RSMQKGVTRA VAAVATTLGP KGRNVIIEQA 51 YGAPKITKDG VTVAKAIEFK DRFENMGAQL VRQVCNKTND LAGDGTTTSA 101 VLVDSIFGEG LKCIAQGTNP IDMKRGMDRA VEVILKSVAK QSRPIKGSED 151 IVQVATISAN GDKEIGEMIG QAMDKVGRDG VITAQDGKTM ATELEVVEGM 201 SVDRGYVSPY FVTDAKAQKA ELEDALVLMS AKKIQSIHSL LPALNHVVRS 251 GRPLLIIADD VESEALTTLI FNKLQGKLKV CCVKAPGFGD NKTAMLQDMS 301 VFTGAQLVGD EGTGLELDAE NFDPSILGSV KKVTVTKDDT VMLNGGGDAA 351 AVKERVELLR ELIKNETSDY NRDKLKERLA KLSGGVAVIK VGGGSEVEVN 401 EKKDRIEDAL CSTRAAVQEG IVAGGGTALL RASKELEALA NDGSLTRDQR 451 TGVTIVRNAI RLPAMTIAAN AGKEGAVIVE KVLEASEEST GYDAQNDKYV 501 NMFEAGIIDP TRVVRVAISD ATSVASLMMT AEAAIVELPK DDSAAAPMGD 551 MGGMGGMGGM GF 
Sample: 175

Mass Spectrum (positive reflector)

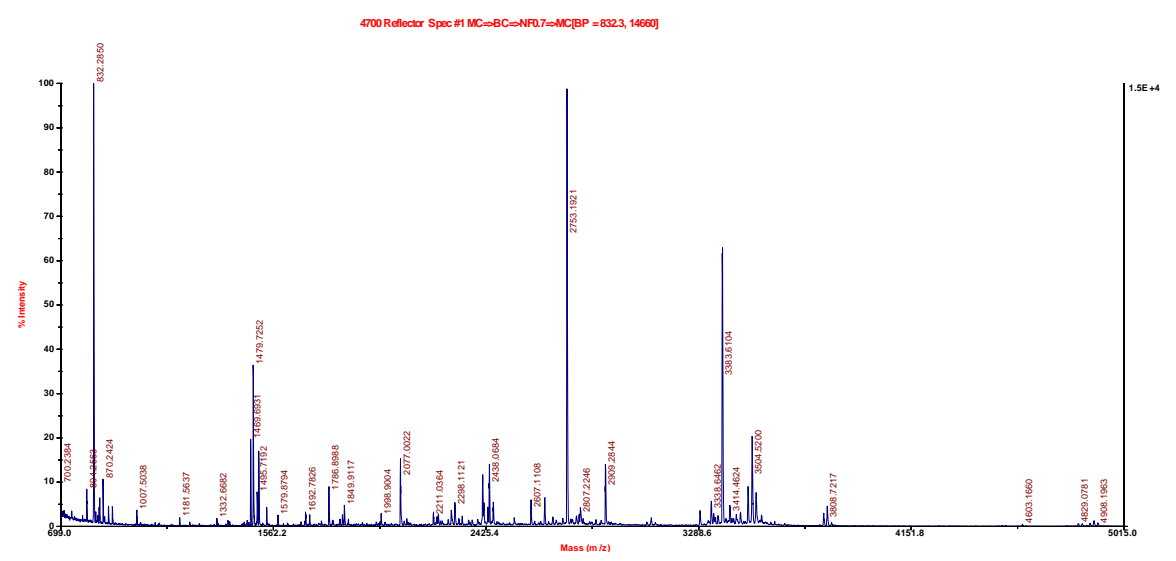

\section{Mascot Score Histogram}

Protein score is $-10^{*} \log (\mathrm{P})$, where $\mathrm{P}$ is the probability that the observed match is a random event. Protein scores greater than 83 are significant $(\mathrm{p}<0.05)$. Protein scores are derived from ions scores as a non-probabilistic basis for ranking protein hits.

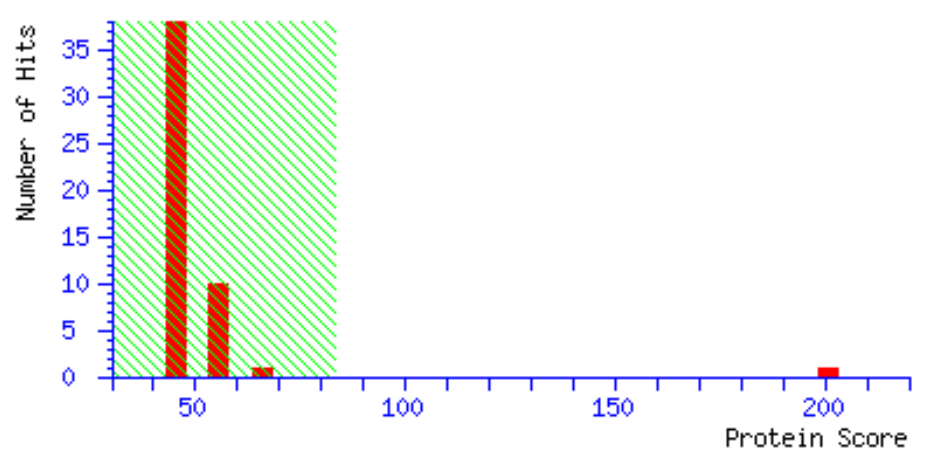

Match to: gi|157869618 Score: 201 Expect: 8.8e-14NADP-dependent alcohol dehydrogenase [Leishmania major strain Friedlin] Nominal mass $\left(\mathrm{M}_{\mathrm{r}}\right)$ : 38345; Calculated pI value: 5.78 NCBI BLAST search of gi|157869618 against nr Unformatted sequence string for pasting into other applications Taxonomy: Leishmania major strain Friedlin Links to retrieve other entries containing this sequence from NCBI Entrez:gi|68126425 from Leishmania major strain Friedlin Variable modifications: Oxidation (M),Carbamidomethyl (C)Cleavage by Trypsin: cuts C-term side of KR unless next residue is PSequence Coverage: $\mathbf{4 1 \%}$

Matched peptides shown in Bold:

1 MPTEAHGWAA LSAKSKLEPF AFQRRDVGPD DVVIAIAYCG VCHSDVHQAR 51 DEWDGSTFPM VPGHEIVGHV TKVGSEVTKY KAGDRVGVGC MVDSCMKCRQ 101 CERGLEQYCV NGASFTYNST QQDKKTPTFG GYSDHVVVRE HFVVSIPDNL 151 DLCAAAPLLC AGVTTFSPLR YWGVKKGTRV GVVGLGGLGH MAVKLANAMG 201 AEVTVFTRSS NKVEEAENLG AHHVVNTNNE QEMNSIQGTL DVIVDTVGMS 251 HDLRPYMMTL DIDGKLALVG MPEHAHPPLD PRRIIASRQC VGGSNIAGMP 301 ETQELLNFCG EHNITATVEK IGIEYINEAY ERILASDVRY RFVIDMASLK $351 \mathrm{KE}$ 


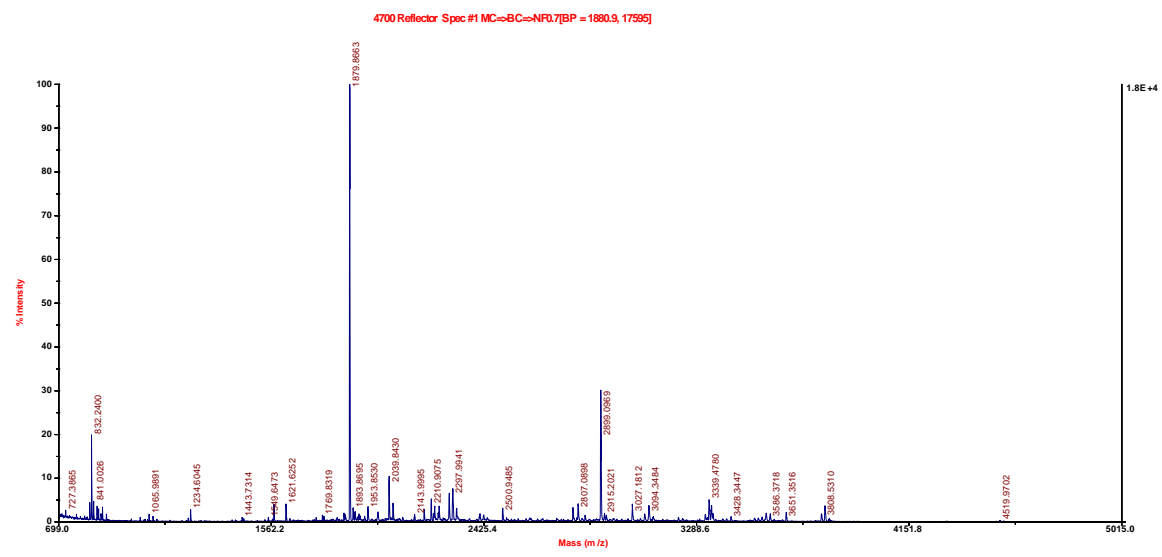

\section{Mascot Score Histogram}

Protein score is $-10^{*} \log (\mathrm{P})$, where $\mathrm{P}$ is the probability that the observed match is a random event. Protein scores greater than 83 are significant $(\mathrm{p}<0.05)$. Protein scores are derived from ions scores as a non-probabilistic basis for ranking protein hits.

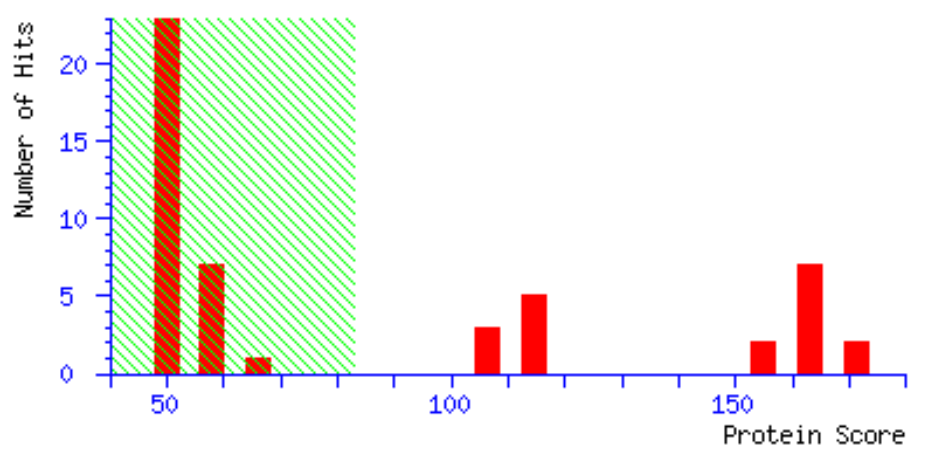

Match to: gi|57015345 Score: 171 Expect: 8.8e-11RecName: Full=Heat shock 70-related protein 1, mitochondrial; Flags: Precursor Nominal mass $\left(\mathrm{M}_{\mathrm{r}}\right)$ : 68288; Calculated $\mathrm{pI}$ value: 5.52 NCBI BLAST search of gi|57015345 against nr Unformatted sequence string for pasting into other applications Taxonomy: Leishmania major Links to retrieve other entries containing this sequence from NCBI Entrez: gi|50299857 from Leishmania major Variable modifications: Oxidation (M),Carbamidomethyl (C) Cleavage by Trypsin: cuts C-term side of KR unless next residue is PSequence Coverage: $\mathbf{1 8 \%}$

Matched peptides shown in Bold:

1 MFARRVCGSA AASAACLARH ESQKVQGDVI GVDLGTTYSC VATMDGDKAR 51 VLENSEGFRT TPSVVAFKGS EKLVGLAAKR QAITNPQSTF YAVKRLIGRR 101 FEDEHIQKDI KNVPYKIVRA GNGDAWVQDG NGKQYSPSQI GAFVLEKMKE 151 TAENFLGHKV SNAVVTCPAY FNDAQRQATK DAGTIAGLNV IRVVNEPTAA 201 ALAYGMDKTK DSLIAVYDLG GGTFDISVLE IAGGVFEVKA TNGDTHLGGE 251 DFDLALSDYI LEEFRKTSGI DLSKERMALQ RVREAAEKAK CELSSAMETE 301 VNLPFITANA DGAQHIQMRI SRSKFEGITQ RLIERSIAPC KQCMKDAGVE 351 LKEINDVVLV GGMTRIRSGG GGEEVLPEGP VRGVNPDEAV ALGAATLGGV 401 LRGKASDLIL VDVTPLSLGT SVVGDVFVPI IPKNTTIPCM RSHIFTTVDD 451 GQTAIKFKVF QGEREIASEN QIRGEFDLSG IPPAPRGVPQ VEVTFDIDAN 501 GICHVTAKDK ATGKTQNITI TANGGLSKEQ IEQMIRDSEQ HAEADRVKRE 551 LVEVRNNAET QLTTAERQLG EWKYVSDAEK ENVKTLVAEL RKAMENPNVA $\mathbf{6 0 1}$ KDDLAAATDK LQKAVMECGR TEYQQAAAAN SGQC 
Sample: 222

Mass Spectrum (positive reflector)

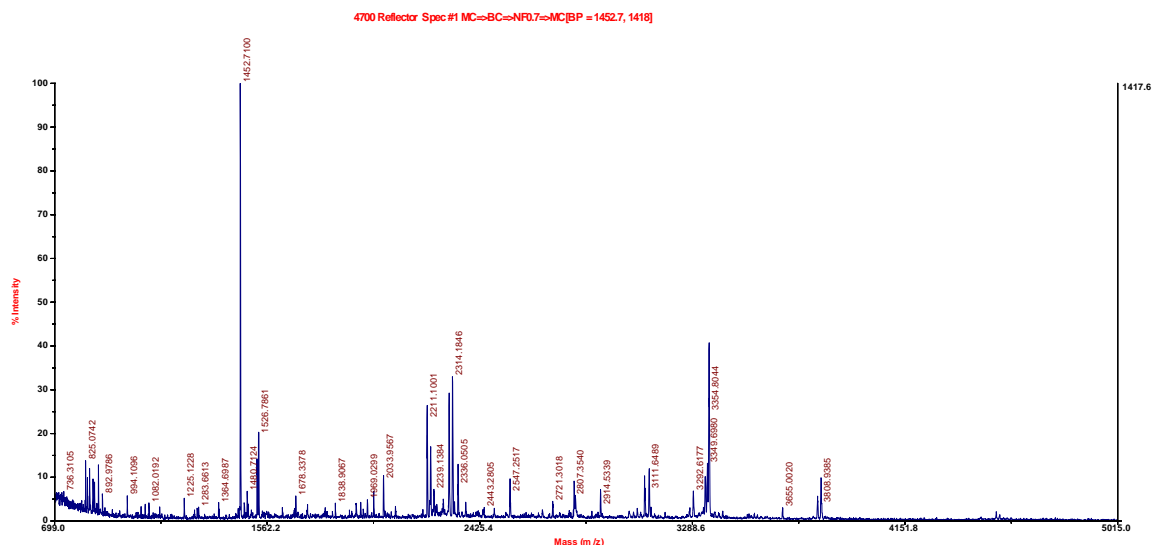

\section{Mascot Score Histogram}

Protein score is $-10 * \log (\mathrm{P})$, where $\mathrm{P}$ is the probability that the observed match is a random event. Protein scores greater than 83 are significant $(\mathrm{p}<0.05)$. Protein scores are derived from ions scores as a non-probabilistic basis for ranking protein hits.

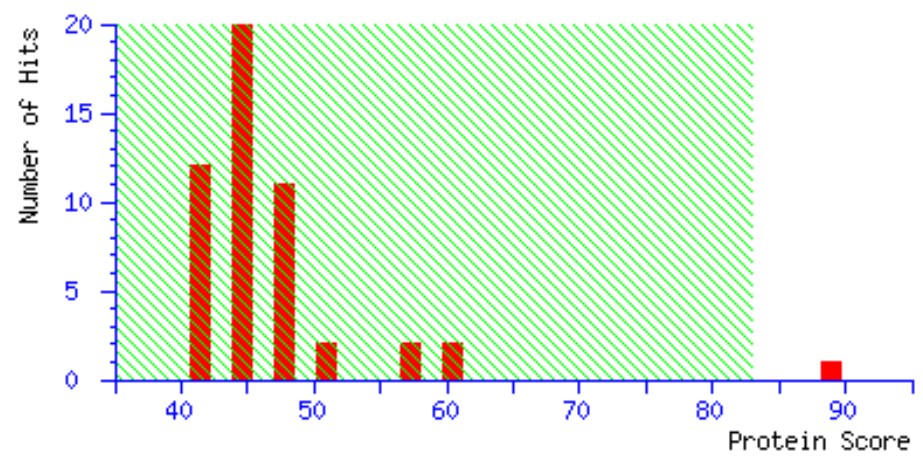

Match to: gi|157868136 Score: 89 Expect: 0.014nucleosome assembly protein [Leishmania major strain Friedlin] Nominal mass $\left(\mathrm{M}_{\mathrm{r}}\right)$ : 39727; Calculated pI value: 4.61NCBI BLAST search of gi|157868136 against nrUnformatted sequence string for pasting into other applications Taxonomy: Leishmania major strain FriedlinLinks to retrieve other entries containing this sequence from NCBI Entrez:gi|68126076 from Leishmania major strain Friedlin Fixed modifications: Carbamidomethyl (C)Variable modifications: Oxidation (M)Cleavage by Trypsin: cuts C-term side of KR unless next residue is PSequence Coverage: 15\% Matched peptides shown in Bold:

1 MPPKNQRDAP VVIPDEDDEG DMMEMGNMLD FQKYLDPDFS KNFMASLPEK 51 IRQRAQVLSA YDKDLSAQQK AYKAKEMDIL RRYDALFEPL LQRRKEIVTG 101 AAVSDEEVKK GMPEEHVNVI SVEVDETDEA AKAADAFGLE GFWLRVLRHH 151 AVIDSTIEPH DEDVLKHLVD IRSSVAEGEY GSFQVIFTFS PNDFFEEETI 201 TATVSIKDDK SELTVSPITW KPGKNVMIHT VTKKQRAKRT GQVRTTTRDV 251 PQLSFFWLFK KKTEAVGDDD AEKDGEEDDE EQRISMLEVL HTCIVPNAVR 301 YYTGEAPNGF SDVDEEDEED EEEEEEEEEI IPRGRGGNRG GRGGRGGRGI 
Sample: 252

Mass Spectrum (positive reflector)

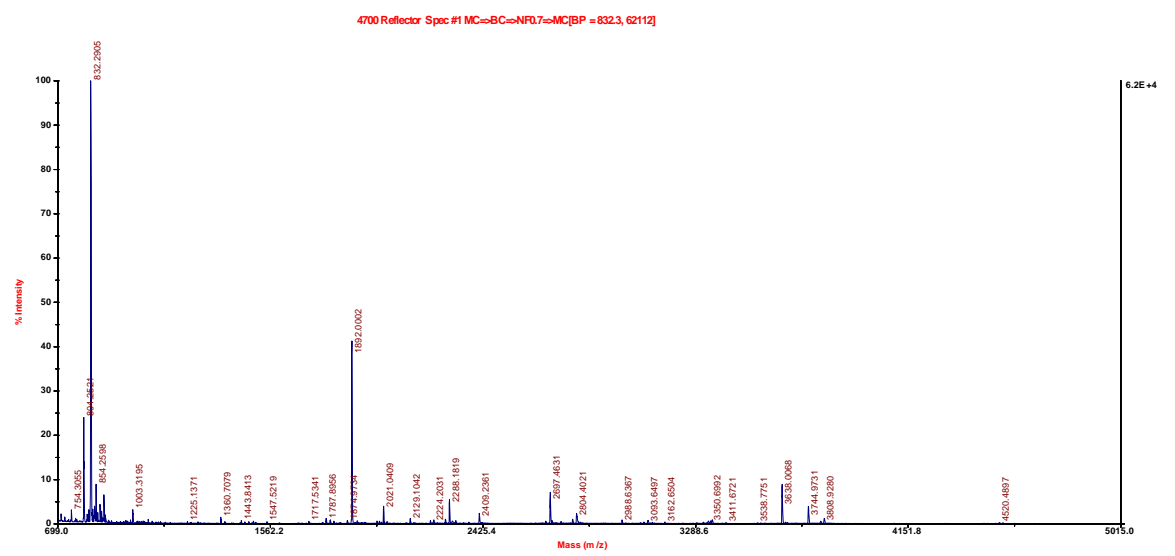

\section{Mascot Score Histogram}

Protein score is $-10 * \log (\mathrm{P})$, where $\mathrm{P}$ is the probability that the observed match is a random event. Protein scores greater than 83 are significant $(\mathrm{p}<0.05)$. Protein scores are derived from ions scores as a non-probabilistic basis for ranking protein hits.

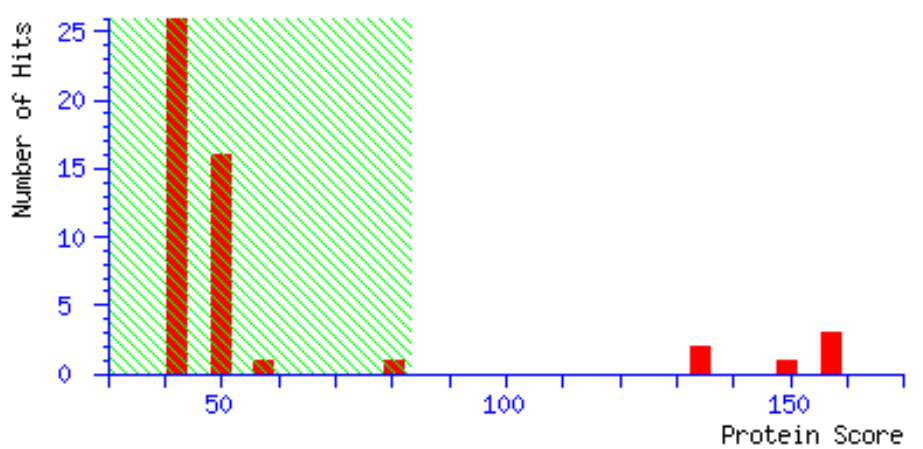

Match to: gi|157870644 Score: 157 Expect: 2.2e-09ATPase beta subunit [Leishmania major strain Friedlin] Nominal mass $\left(\mathrm{M}_{\mathrm{r}}\right)$ : 56541; Calculated pI value: 5.14 NCBI BLAST search of gi|157870644 against nr Unformatted sequence string for pasting into other applications Taxonomy: Leishmania major strain FriedlinLinks to retrieve other entries containing this sequence from NCBI Entrez:gi|68126939 from Leishmania major strain Friedlin Fixed modifications: Carbamidomethyl (C)Variable modifications: Oxidation (M)Cleavage by Trypsin: cuts $\mathrm{C}$-term side of KR unless next residue is $\mathrm{P}$ Sequence Coverage: $\mathbf{3 1 \%}$ Matched peptides shown in Bold:

1 MLSRVQSAMI RRAAGVRAAS SAVAAAAAKP AEHKGRVGYV SQVIGAVVDV 51 HFSEGVPPVL TALDVTEDLG RDEPLTLEIV QHLDANTGRC IAMQTTDLLK 101 LKSKVVSTGG NISVPVGRET LGRIFNVLGD AIDQRGPVGE KMRMAIHAEA 151 PKLADQAAED TILTTGIKVI DLILPYCKGG KIGLFGGAGV GKTVIIMELI 201 NNVAKGHGGF SVFAGVGERT REGTDLYLEM MQSKVIDLKG ESKCVLVYGQ 251 MNEPPGARAR VAQSALTMAE YFRDVEGQNV LLFIDNIFRF TQANSEVSAL 301 LGRIPAAVGY QPTLAEDLGM LQERITSTTK GSITSVQAVY VPADDITDPA 351 PATTFSHLDA TTVLDRAVAE SGIYPAVNPL ECASRIMDPD VIDVDHYNVA 401 QDIVQMLTKY KELQDIIAVL GIDELSEEDK VVVDRARKVT RFLSQPFQVA 451 EVFTGMTGHY VQLVDTVESF SGLLMGSYDQ IPEMAFYMVG GIKSVLEKAK 501 AMAEEAAAME KQRRARQAAN ASDSQ 


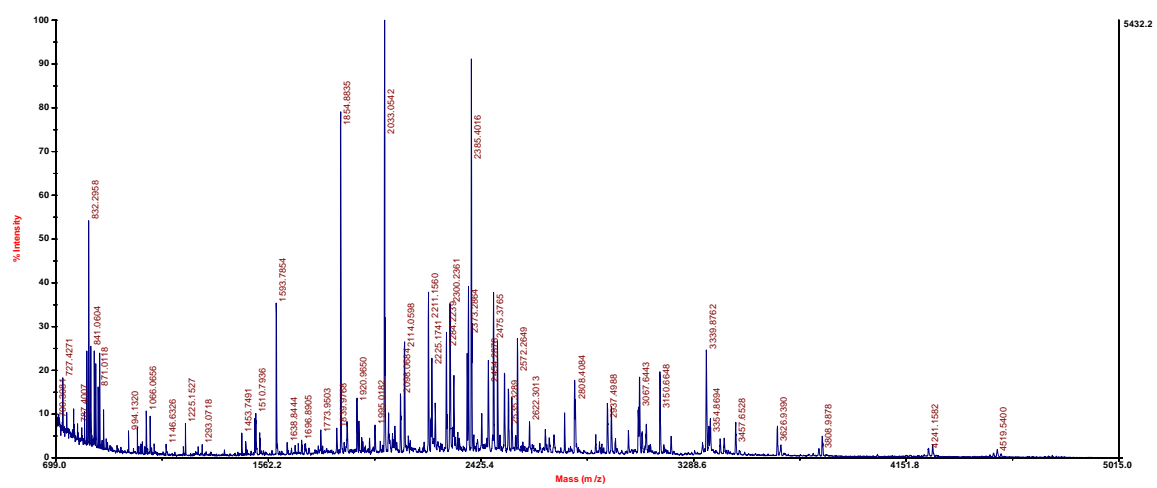

\section{Mascot Score Histogram}

Protein score is $-10^{*} \log (\mathrm{P})$, where $\mathrm{P}$ is the probability that the observed match is a random event. Protein scores greater than 83 are significant $(\mathrm{p}<0.05)$. Protein scores are derived from ions scores as a non-probabilistic basis for ranking protein hits.

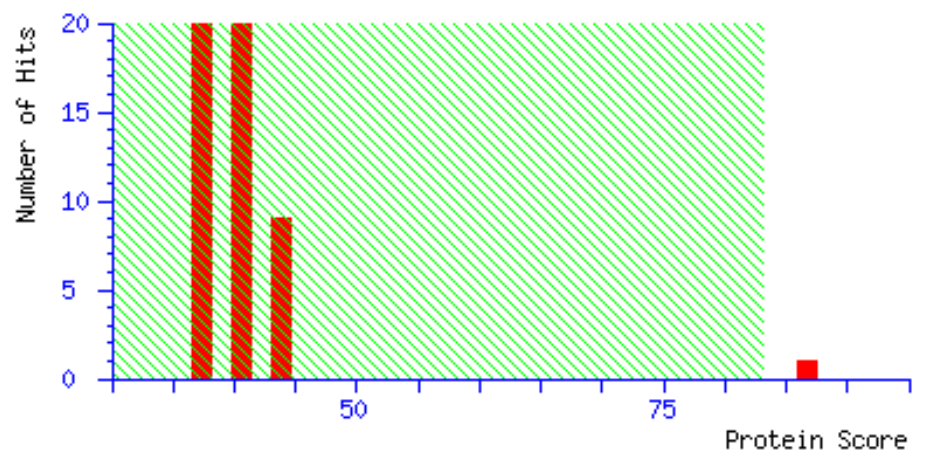

Match to: gi|157877007 Score: 87 Expect: 0.023dihydrolipoamide acetyltransferase precursor [Leishmania major strain Friedlin] Nominal mass $\left(\mathrm{M}_{\mathrm{r}}\right)$ : 49062; Calculated pI value: 7.01 NCBI BLAST search of gi|157877007 against $\mathrm{nr}$ Unformatted sequence string for pasting into other applications Taxonomy: Leishmania major strain Friedlin Links to retrieve other entries containing this sequence from NCBI Entrez:gi|68129918 from Leishmania major strain Friedlin Fixed modifications: Carbamidomethyl (C)Variable modifications: Oxidation (M)Cleavage by Trypsin: cuts C-term side of KR unless next residue is P Sequence Coverage: 17\% Matched peptides shown in Bold:

1 MLRCRAVSKL ATLAALRFLT ITPIPMPALS PTMEKGKITE WCKQPGDFIR 51 PGDTFCNIET DKAVVSYDNA TEEGFFARVI TSPGEETVVG QTVCLIVDEK 101 EGVHSDEVKN WKPEAEEAPA AAAEEAPAAP AATTPVAAAP VAASGDRVKA 151 SPYARKMAAE KNVSLRGIKG TGGGVGRITS KDVAAAVASG TASSAAEVAA 201 PAKTAATAAL AAPAKPAAAK GTPPANPNFT DIPVTTMRSV IAKRLHQSKN 251 LEIPHYYLFD DCRVDNMLAL IKQLNAKGNG EYKITVNDYI VKAVARANTL 301 VPEVNSSWQG DFIRQYATVD VSVAVATPTG LITPIIRNAQ AKGLVEISKE 351 TKALAKKARD GTLQPSEFQG GTCSVSNLGA TGIPGFTAII NPPQAMILAV 401 GSAKPRAEIV KSEETGEFEM TGRVENVVSF SASFDHRIVD GALGAKWFQH 451 FHDAMENPLS LLL 


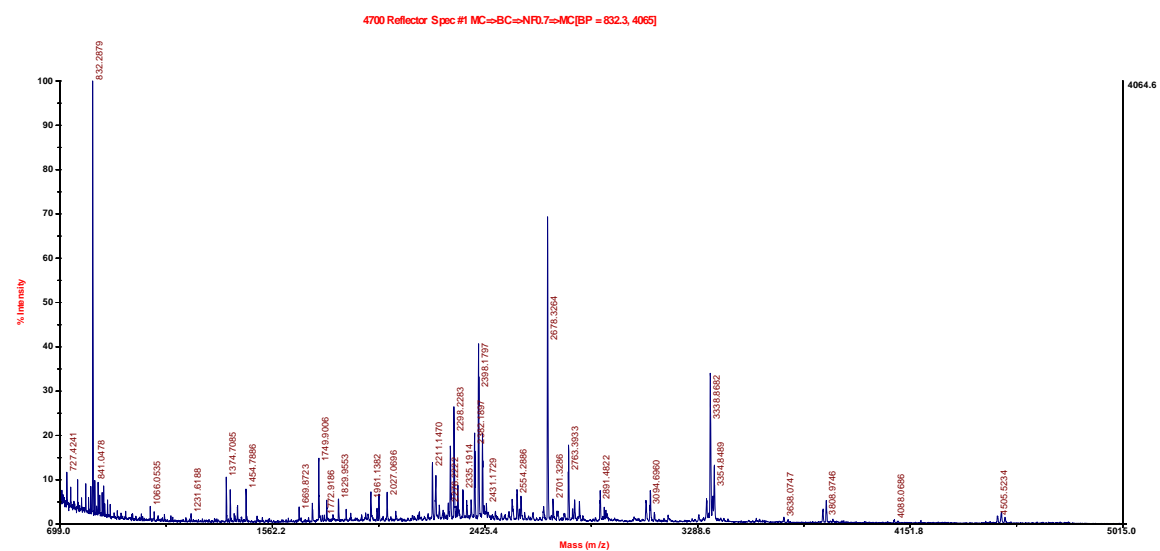

\section{Mascot Score Histogram}

Protein score is $-10^{*} \log (\mathrm{P})$, where $\mathrm{P}$ is the probability that the observed match is a random event. Protein scores greater than 83 are significant $(\mathrm{p}<0.05)$. Protein scores are derived from ions scores as a non-probabilistic basis for ranking protein hits.

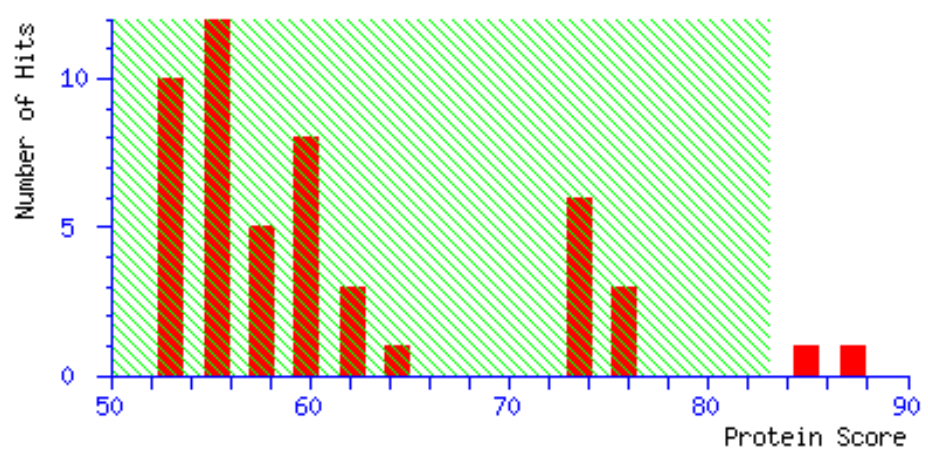

Match to: gi|1698880 Score: 87 Expect: 0.021 protein antigen LmSTI1 [Leishmania major] Nominal mass $\left(M_{\mathrm{r}}\right)$ : 62507; Calculated pI value: 5.91 NCBI BLAST search of gi|1698880 against nr Unformatted sequence string for pasting into other applications Taxonomy: Leishmania major Fixed modifications: Carbamidomethyl (C)Variable modifications: Oxidation (M)Cleavage by Trypsin: cuts C-term side of KR unless next residue is P Sequence Coverage: $\mathbf{1 8 \%}$

Matched peptides shown in Bold:

1 DATELKNKGN EEFSAGRYVE AVNYFSKAIQ LDEQNSVLYS NRSACFAAMQ 51 KYKDALDDAD KCISIKPNWA KGYVRRGAAL HGMRRYDDAI AAYEKGLKVD 101 PSNSGCAQGV KDVQVAKARE ARDPIARVFT PEAFRKIQEN PKLSLLMLQP 151 DYVKMVDTVI RDPSQGRLYM EDQRFALTLM YLSGMKIPND GDGEEEERPS 201 AKAAETAKPK EEKPLTDNEK EALALKEEGN KLYLSKKFEE ALTKYQEAQV 251 KDPNNTLYIL NVSAVYFEQG DYDKCIAECE HGIEHGRENH CDYTIIAKLM 301 TRNALCLQRQ RKYEAAIDLY KRALVEWRNP DTLKKLTECE KEHQKAVEEA 351 YIDPEIAKQK KDEGNQYFKE DKFPEAVAAY TEAIKRNPAE HTSYSNRAAA 401 YIKLGAFNDA LKDAEKCIEL KPDFVKGYAR KGHAYFWTKQ YNRALQAYDE 451 GLKVDPSNAD CKDGRYRTIM KIQEMASGQS ADGDEAARRA MDDPEIAAIM 501 QDSYMQLVLK EMQNDPTRIQ EYMKDSGISS KINKLISAGI IRFGQ 
Sample: 356

Mass Spectrum (positive reflector)

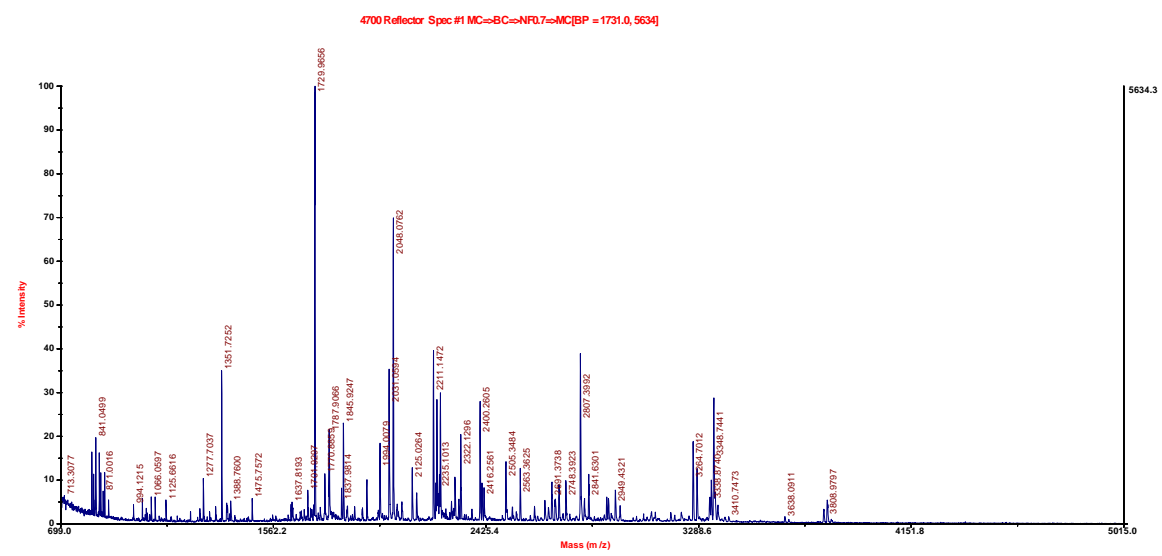

\section{Mascot Score Histogram}

Protein score is $-10^{*} \log (\mathrm{P})$, where $\mathrm{P}$ is the probability that the observed match is a random event. Protein scores greater than 83 are significant $(\mathrm{p}<0.05)$. Protein scores are derived from ions scores as a non-probabilistic basis for ranking protein hits.

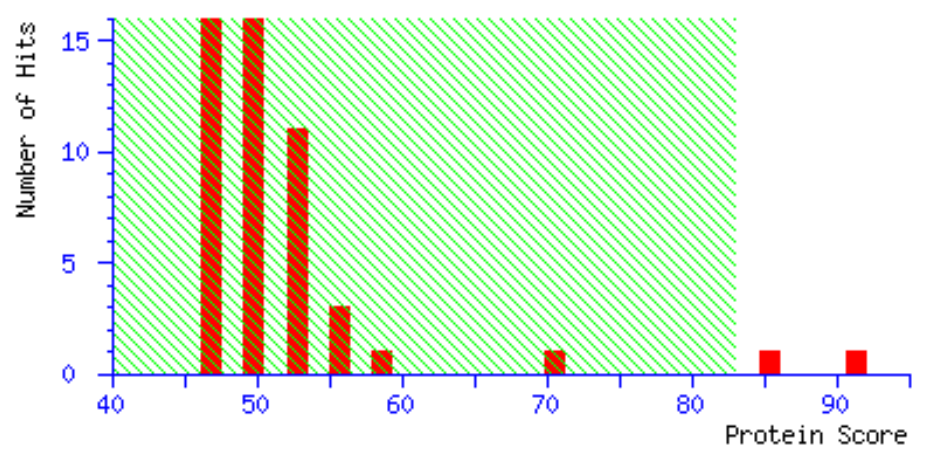

Match to: gi|157871157 Score: 91 Expect: 0.008 heat shock protein 70-related protein [Leishmania major] Nominal mass $\left(\mathrm{M}_{\mathrm{r}}\right)$ : 71001; Calculated pI value: 5.04 NCBI BLAST search of gi|157871157 against nr Unformatted sequence string for pasting into other applications Taxonomy: Leishmania major strain FriedlinLinks to retrieve other entries containing this sequence from NCBI Entrez:gi|68127196 from Leishmania major strain Friedlin Fixed modifications: Carbamidomethyl (C)Variable modifications: Oxidation (M)Cleavage by Trypsin: cuts C-term side of KR unless next residue is PSequence Coverage: 19\%

Matched peptides shown in Bold:

1 MSSTNAIGID LGTTYSCVGV FKNEQVDIIA NDQGNRTTPS YVAFTETERL 51 IGDAAKNQVA MNPSNTVFDA KRMIGRKFDD PDLQSDMKHW PFKVIVKDGK 101 PVISVEYQNQ TKTFFPEEIS AMVLQKMKET AEAYLGTTVK DAVITVPAYF 151 NDSQRQATKD AGSIAGLNVL RIINEPTAAA IAYGMDRKGD KGEKNVLIFD 201 LGGGTFDVTL LTIESGVFEV KATAGDTHLG GEDFDNRLVD YFATELKMRC 251 GKDCRGNARA TRRLRTACER VKRTLSSSTT ANIEIDALYE GNDFFSKITR 301 ARFEEMCRDQ FEKCLEPVKK VLADADMKPQ DVDDVVLVGG STRIPKIQQI 351 VSQFFGGKEL NRSINPDEAV AYGAAVQAHI LAGGHSSKTD GLLLLDVTPL 401 SLGVETSGGV MSVLIPRNST MPVQKTQTYS NNADNQRNVV IKVYEGERPL 451 VSQCQCLGTF TLTDIPPMPR GKARINVTFD VNTDGILIVS AVEESGGRKE 501 AITIQNDTGR LSKEQIESMV REAEKFAEED RMNSERVEAR NTLENYTFSM 551 RATLDDPDVQ NGITQGDRQQ IQDAVNAASS WLEKNREATK EEYMEQTKLI 601 EGIAHPILSE FYKKRVMEAP PSAGPKDGAP SDEVPHAEDV D 
Sample: 405

Mass Spectrum (positive reflector)

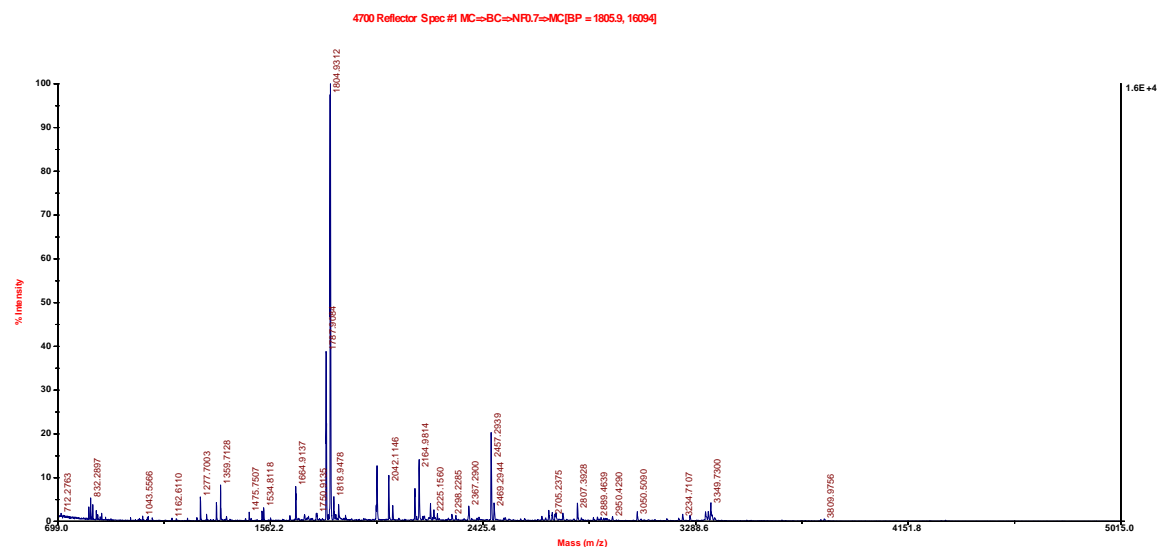

\section{Mascot Score Histogram}

Protein score is $-10^{*} \log (\mathrm{P})$, where $\mathrm{P}$ is the probability that the observed match is a random event. Protein scores greater than 83 are significant $(\mathrm{p}<0.05)$. Protein scores are derived from ions scores as a non-probabilistic basis for ranking protein hits.

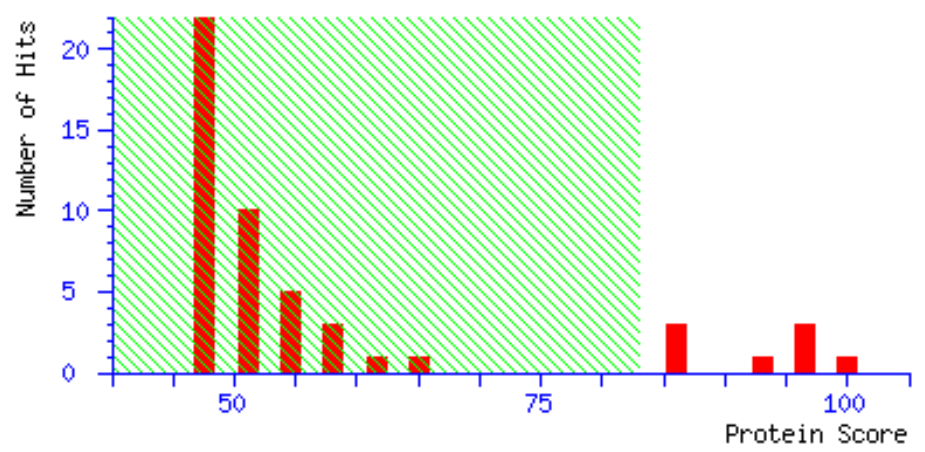

Match to: gi|146080653 Score: 100 Expect: 0.0011alpha tubulin [Leishmania infantum JPCM5] Nominal mass $\left(M_{r}\right)$ : 36306; Calculated pI value: 6.78 NCBI BLAST search of gi|146080653 against nr Unformatted sequence string for pasting into other applications Taxonomy: Leishmania infantum JPCM5 Links to retrieve other entries containing this sequence from NCBI Entrez:gi|134068142 from Leishmania infantum Variable modifications: Oxidation (M),Carbamidomethyl (C),Pyro-carbamidomethyl (N-term C) Cleavage by Trypsin: cuts C-term side of KR unless next residue is $\mathrm{P}$ Sequence Coverage: $\mathbf{1 8 \%}$

Matched peptides shown in Bold:

1 MHTDTHAHTP PSSRSAALLL LLLPPCAGRL PRVSSPHLAL SLPPPLPSWR

51 TQNMRDAHTR TPTEKKTRSS SLSFFEQTPL NRLLTPLSSF SAMREAICIH 101 IGQAGCQVGN TCWELFCLEH GIQPDGSMPS DKCIGVEDDA FNTFFSETGA 151 GKHVPRCIFL DLEPTVVDEV RTGTYRQLFN PEQLVSGKED AANNYARGHY 201 TIGKEIVDLA LDRIRKLADN CTGLQGFMVF RESPFLLPLS LPLPLPLFPP 251 LPREGNTKEK IAKDSDVYMM RHKDEINPPM PPPLPSLPPC VCVRVFFLLL 301 SVAVVPLLFP FYVLVCLLFS PFASLFL 
Sample: 407

Mass Spectrum (positive reflector)

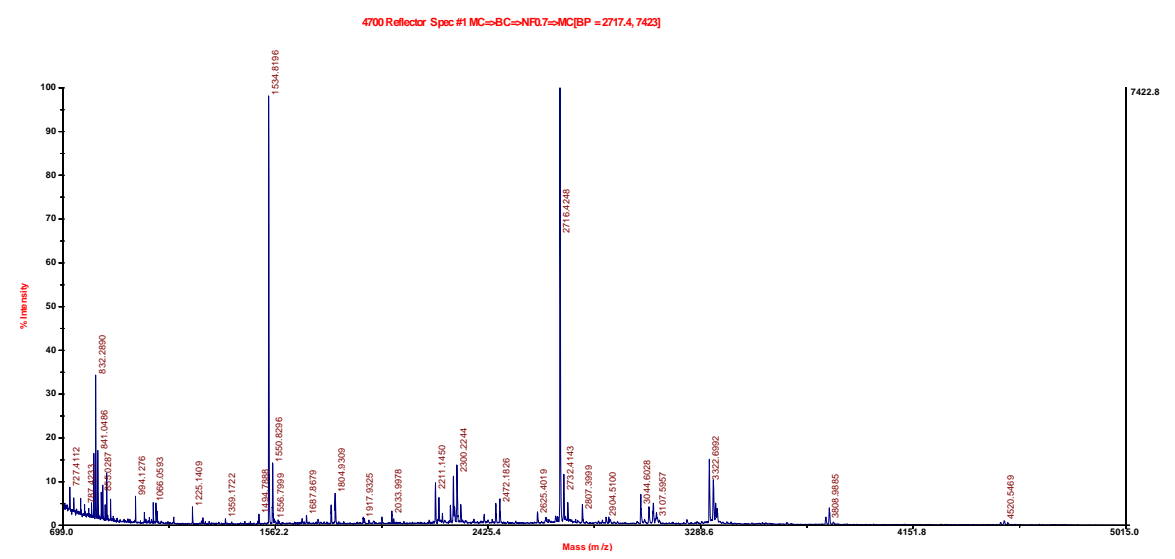

\section{Mascot Score Histogram}

Protein score is $-10^{*} \log (\mathrm{P})$, where $\mathrm{P}$ is the probability that the observed match is a random event. Protein scores greater than 83 are significant $(\mathrm{p}<0.05)$. Protein scores are derived from ions scores as a non-probabilistic basis for ranking protein hits.

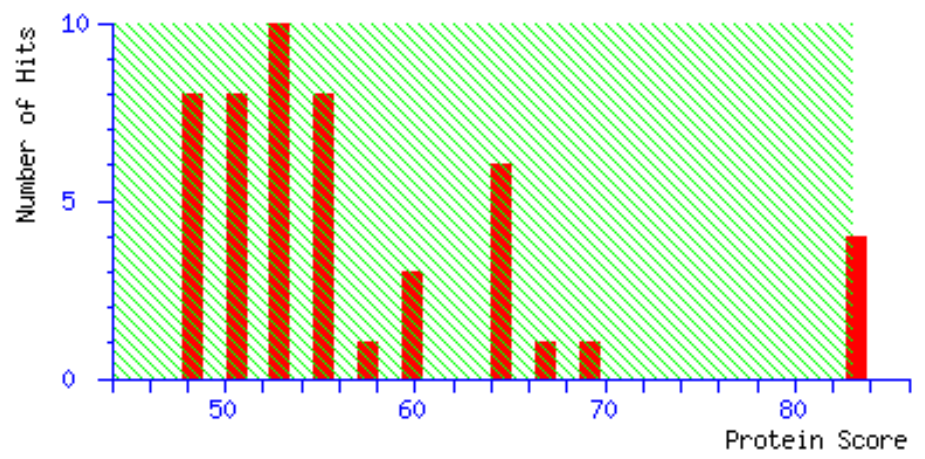

Match to: gi|146086967 Score: 83 Expect: 0.053 peroxidoxin [Leishmania infantum JPCM5] Nominal mass $\left(M_{\mathrm{r}}\right)$ : 25354; Calculated pI value: 6.43NCBI BLAST search of gi|146086967 against nr Unformatted sequence string for pasting into other applications Taxonomy: Leishmania infantum JPCM5 Links to retrieve other entries containing this sequence from NCBI Entrez:gi|16751316 from Leishmania infantumgi|134069782 from Leishmania infantum Variable modifications: Carbamidomethyl (C),Oxidation (M)Cleavage by Trypsin: cuts C-term side of KR unless next residue is P Sequence Coverage: 16\%

Matched peptides shown in Bold:

1 MLRRLPTSCF LKRSQFRGFA ATSPLLNLDY QMYRTATVRE AAPQFSGQAV 51 VNGAIKDINM NDYKGKYIVL FFYPMDFTFV CPTEIIAFSD RHADFEKLNT 101 QVVAVSCDSV YSHLAWVNTP RKKGGLGEMH IPVLADKSME IARDYGVLIE 151 ESGIALRGLF IIDKKGILRH STINDLPVGR NVDEALRVLE AFQYADENGD 201 AIPCGWKPGQ PTLDTTKAGE FFEKNM 


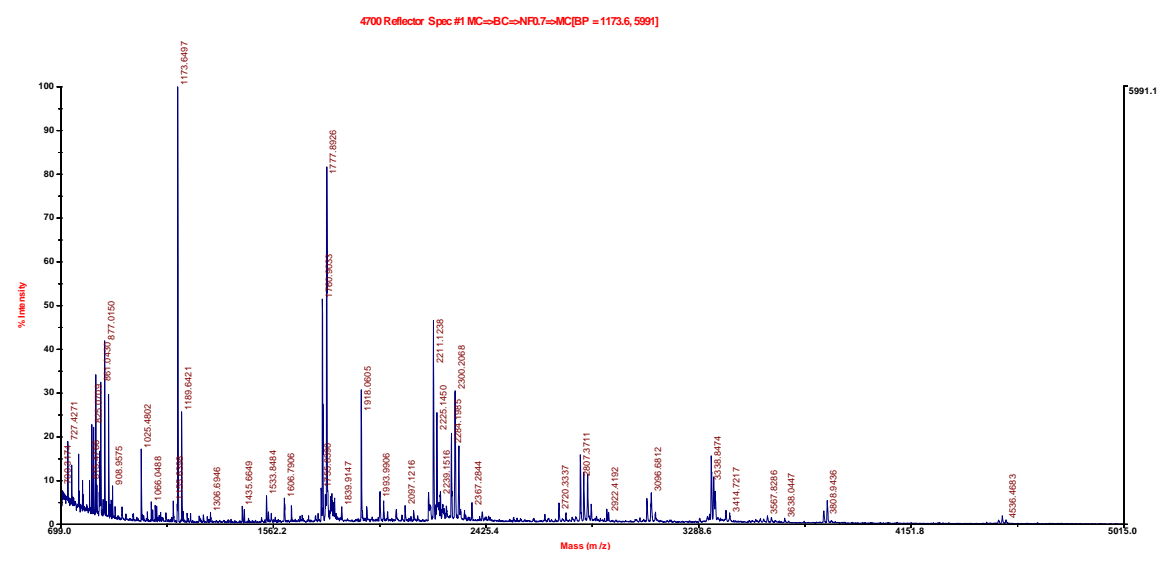

\section{Mascot Score Histogram}

Protein score is $-10^{*} \log (\mathrm{P})$, where $\mathrm{P}$ is the probability that the observed match is a random event. Protein scores greater than 83 are significant $(\mathrm{p}<0.05)$. Protein scores are derived from ions scores as a non-probabilistic basis for ranking protein hits.

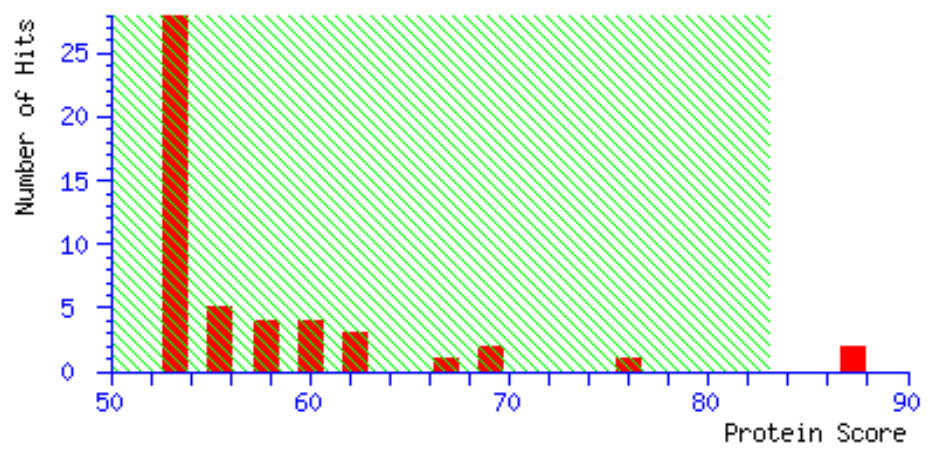

Match to: gi|157865592 Score: 87 Expect: 0.02114-3-3 protein [Leishmania major strain Friedlin] Nominal mass $\left(\mathrm{M}_{\mathrm{r}}\right)$ : 29126; Calculated $\mathrm{pI}$ value: 5.19 NCBI BLAST search of gi|157865592 against $\mathrm{nr}$ Unformatted sequence string for pasting into other applications Taxonomy: Leishmania major strain FriedlinLinks to retrieve other entries containing this sequence from NCBI Entrez:gi|68124800 from Leishmania major strain Friedlingi|257900393 from Leishmania major Variable modifications: Carbamidomethyl (C), Oxidation (M)Cleavage by Trypsin: cuts C-term side of KR unless next residue is P Sequence Coverage: $27 \%$

Matched peptides shown in Bold:

1 MTNVFKVPEK REELVYTAKI AEQCERHDEI LFCMKRAVKM NPRLSSEERN

51 LLSAAYKYII SARRACWRSM SSMAHKEDSH KGKTASLFNG FQHQVEKELA

101 EICSDILELL DKYLIPAADN DESKVYYYKL KGDYHRYFAE VESGSDTQKN

151 LALEAYKKAS EFTTSLKPTS PIRLGLALNF SVFYYEILRS PDKGCQLARQ

201 AFEEALSDPE VLDEEQHKES ALIMQLLRDN LALWTEDSRP EGQDDGTAME

251 ELE 


\section{Mascot Score Histogram}

Protein score is $-10^{*} \log (\mathrm{P})$, where $\mathrm{P}$ is the probability that the observed match is a random event. Protein scores greater than 83 are significant $(\mathrm{p}<0.05)$. Protein scores are derived from ions scores as a non-probabilistic basis for ranking protein hits.

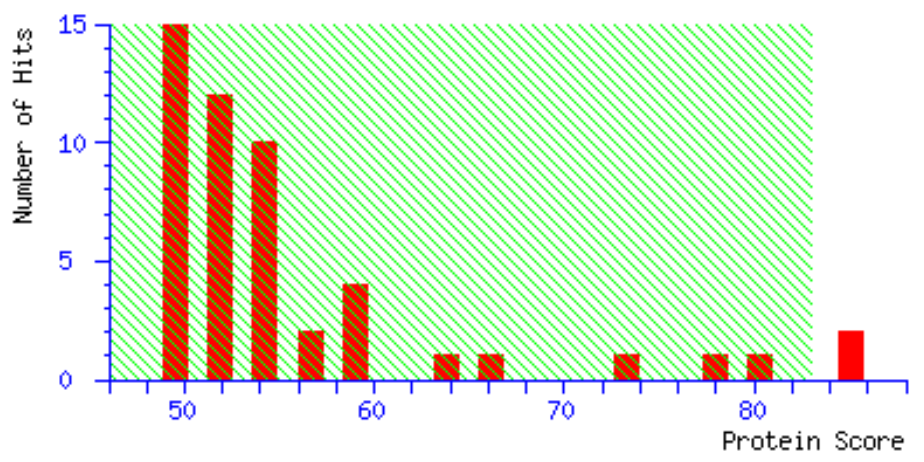

Match to: gi|157864162 Score: 85 Expect: 0.039 hypothetical protein [Leishmania major strain Friedlin] Nominal mass $\left(\mathrm{M}_{\mathrm{r}}\right)$ : 30868; Calculated $\mathrm{pI}$ value: 5.34 NCBI BLAST search of gi|157864162 against nr Unformatted sequence string for pasting into other applications Taxonomy: Leishmania major strain Friedlin Links to retrieve other entries containing this sequence from NCBI Entrez:gi|68124086 from Leishmania major strain Friedlin Variable modifications: Carbamidomethyl (C),Oxidation (M)Cleavage by Trypsin: cuts C-term side of KR unless next residue is P Sequence Coverage: 14\%

Matched peptides shown in Bold:

1 MDPLAGLTTG SRNVIDDFFR WSRLSLDKFK RDLTVEASAF QAGNLWREQY

$\mathbf{5 1}$ TKAEVAQMLN GQLALMLGVV DTQMEGTTAA SAELMRAVLR EADRQRVTLD

101 IDVKSVLNNA GGVNAMGEHG RQLMSGPTGR LAPLTVEEAS GEAARQLAEA

151 NAEVKRLQAK LQQVTDAYTQ VMRGRSSDTE NLLSMQDAMN DKERLAAELA

201 RRCQGQDPSL AATVQELRAE VAEAKRELAS RLHQSTQYQQ VKHLLAQRNE 


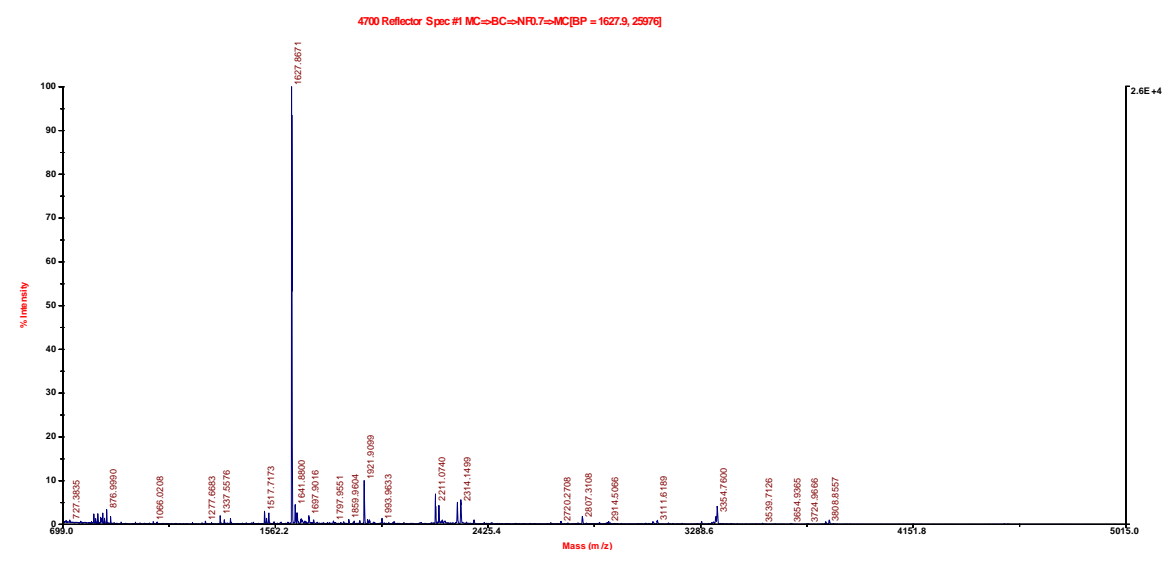

\section{Mascot Score Histogram}

Protein score is $-10^{*} \log (\mathrm{P})$, where $\mathrm{P}$ is the probability that the observed match is a random event. Protein scores greater than 83 are significant $(\mathrm{p}<0.05)$. Protein scores are derived from ions scores as a non-probabilistic basis for ranking protein hits.

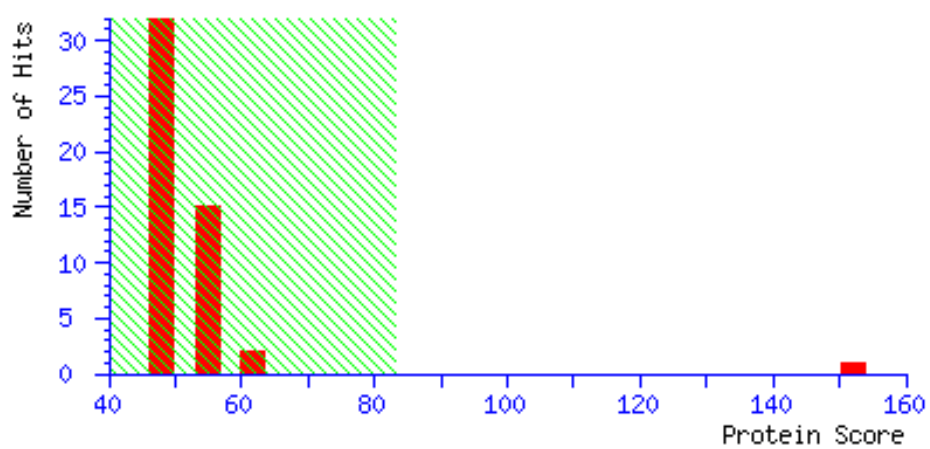

Match to: gi|157870822 Score: 152 Expect: 7e-09 hypothetical protein [Leishmania major strain Friedlin] Nominal mass $\left(M_{r}\right)$ : 32835; Calculated pI value: 5.52 NCBI BLAST search of gi|157870822 against nr Unformatted sequence string for pasting into other applications Taxonomy: Leishmania major strain Friedlin Links to retrieve other entries containing this sequence from NCBI Entrez:gi|68127028 from Leishmania major strain Friedlin Variable modifications: Carbamidomethyl (C),Oxidation (M)Cleavage by Trypsin: cuts C-term side of KR unless next residue is P Sequence Coverage: $35 \%$

Matched peptides shown in Bold:

1 MQKTILQILR EQDDASSSCV LALLKGNASF QCLSKSEGED ILKRDNEDAE 51 KLSDGIRIAI RKGIVSGKPD VSPVNKLNVV GLSAQEVTDK IVAALPSKNG 101 NVIILQGLSG TGKGTTVSKL KDALPKCVTW SNGNIFRSYT YLCNEVLAAQ 151 GKEITEESLT DELLSSVEKR VTFVKCEDGM FHTMLDGTRR VADVQNTLLK 201 TPLISSKVPT VAQQTQGEVI RFGAGAVKQL SADGYNVILE GRSQTLDYIS 251 SPLRFELIIP DVEVLGQRRA AQRVMAKALE MLDDSASDEE VSKVLVKAVE 301 TLQ 
Sample: 426

Mass Spectrum (positive reflector)

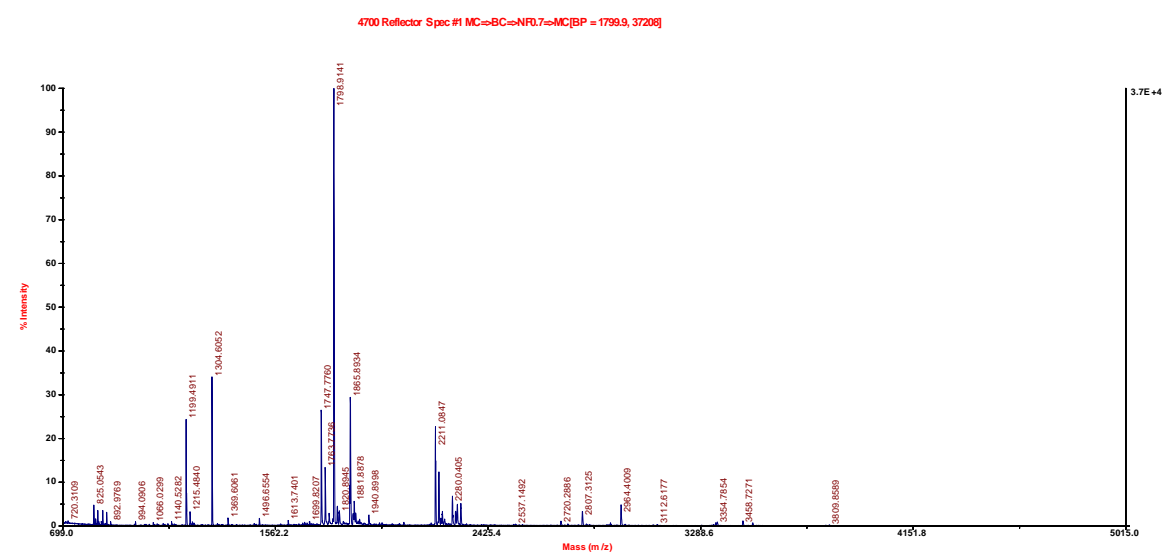

\section{Mascot Score Histogram}

Protein score is $-10^{*} \log (\mathrm{P})$, where $\mathrm{P}$ is the probability that the observed match is a random event. Protein scores greater than 83 are significant $(\mathrm{p}<0.05)$. Protein scores are derived from ions scores as a non-probabilistic basis for ranking protein hits.

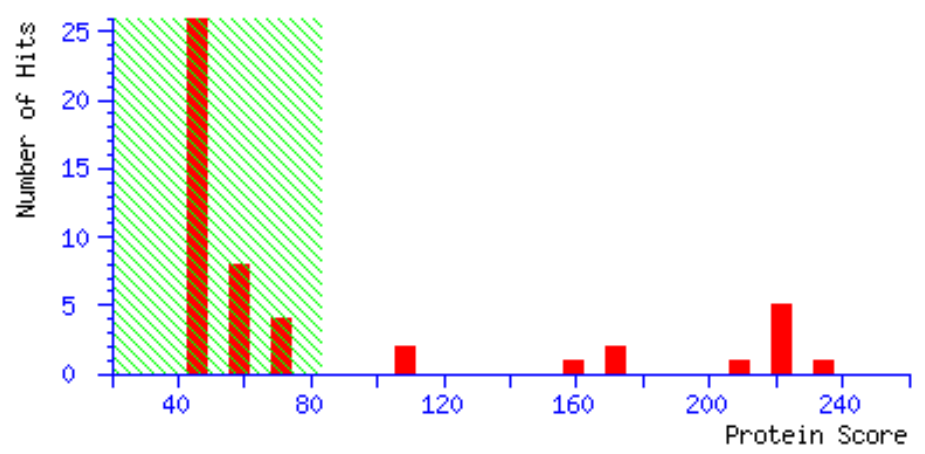

Match to: gi|157872022 Score: 234 Expect: 4.4e-17 activated protein kinase c receptor (LACK); guanine nucleotide-binding protein beta subunit-like protein [Leishmania major] Nominal mass $\left(\mathrm{M}_{\mathrm{r}}\right)$ : 34378 ; Calculated pI value: 6.05 NCBI BLAST search of gi|157872022 against nr Unformatted sequence string for pasting into other applications Taxonomy: Leishmania major strain Friedlin Links to retrieve other entries containing this sequence from NCBI Entrez:gi|157872024 from Leishmania major strain Friedlingi|68127629 from Leishmania major strain Friedlingi|68127630 from Leishmania major strain Friedlin Variable modifications: Carbamidomethyl (C),Oxidation (M)Cleavage by Trypsin: cuts C-term side of KR unless next residue is P Sequence Coverage: $\mathbf{5 0 \%}$ Matched peptides shown in Bold:

1 MNYEGHLKGH RGWVTSLACP QQAGSYIKVV STSRDGTAIS WKANPDRHSV 51 DSDYGLPNHR LEGHTGFVSC VSLAHATDYA LTASWDRSIR MWDLRNGQCQ 101 RKFLKHTKDV LAVAFSPDDR LIVSAGRDNV IRVWNVAGEC MHEFLRDGHE 151 DWVSSICFSP SLEHPIVVSG SWDNTIKVWN VNGGKCERTL KGHSNYVSTV 201 TVSPDGSLCA SGGKDGAALL WDLSTGEQLF KINVESPINQ IAFSPNRFWM 251 CVATERSLSV YDLESKAVIA ELTPDGAKPS ECISIAWSAD GNTLYSGHKD 301 NLIRVWSISD AE 
Sample: 478

Mass Spectrum (positive reflector)

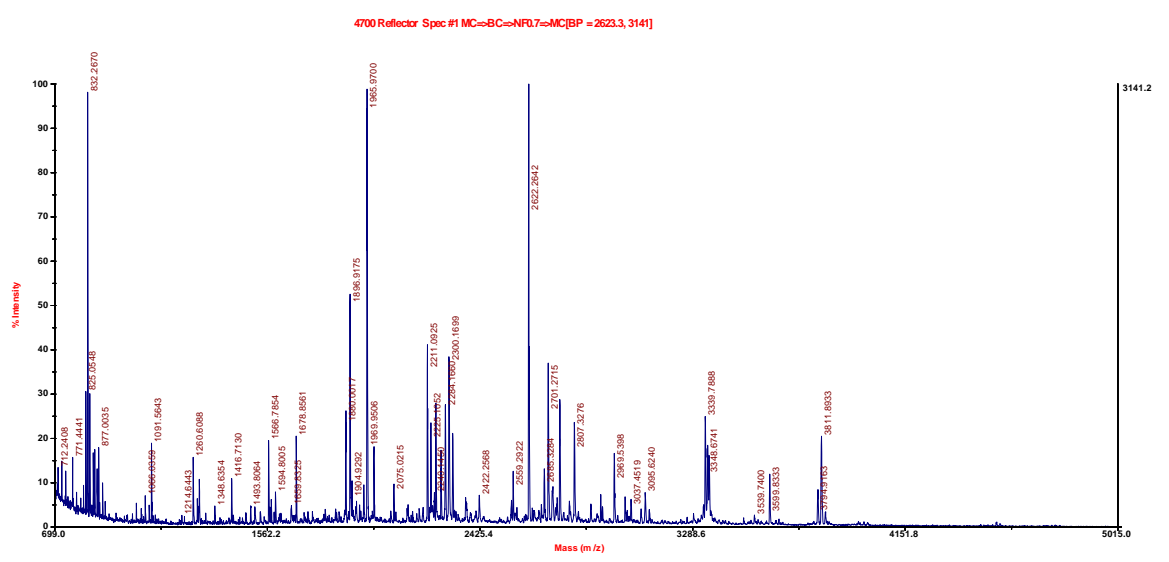

Mascot Score Histogram

Protein score is $-10 * \log (\mathrm{P})$, where $\mathrm{P}$ is the probability that the observed match is a random event. Protein scores greater than 83 are significant $(\mathrm{p}<0.05)$. Protein scores are derived from ions scores as a non-probabilistic basis for ranking protein hits.

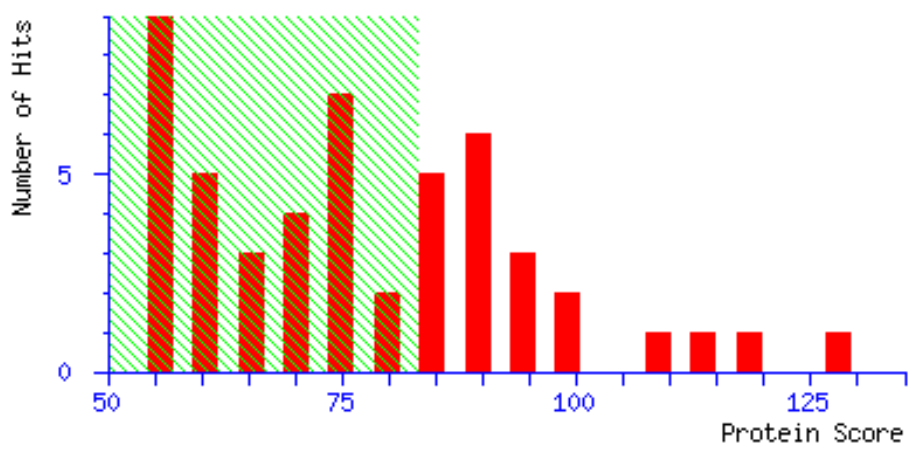

Match to: gi|157872028 Score: 128 Expect: 1.8e-06 heat-shock protein hsp70 [Leishmania major strain Friedlin] Nominal mass $\left(M_{r}\right)$ : 71608; Calculated pI value: 5.30 NCBI BLAST search of gi|157872028 against nr Unformatted sequence string for pasting into other applications Taxonomy: Leishmania major strain Friedlin Links to retrieve other entries containing this sequence from NCBI Entrez:gi|157872030 from Leishmania major strain Friedlingi|68127632 from Leishmania major strain Friedlingi|68127633 from Leishmania major strain Friedlin Variable modifications: Carbamidomethyl (C),Oxidation (M)Cleavage by Trypsin: cuts C-term side of KR unless next residue is P Sequence Coverage: $\mathbf{2 9 \%}$

Matched peptides shown in Bold:

1 MTFDGAIGID LGTTYSCVGV WQNERVDIIA NDQGNRTTPS YVAFTDSERL

51 IGDAAKNQVA MNPHNTVFDA KRLIGRKFND SVVQSDMKHW PFKVTTKGDD

101 KPVISVQYRG EEKTFTPEEI SSMVLLKMKE TAEAYLGKQV KKAVVTVPAY

151 FNDSQRQATK DAGTIAGLEV LRIINEPTAA AIAYGLDKGD DGKERNVLIF

201 DLGGGTFDVT LLTIDGGIFE VKATNGDTHL GGEDFDNRLV TFFTEEFKRK

251 NKGKNLASSH RALRRLRTAC ERAKRTLSSA TQATIEIDAL FENIDFQATI

301 TRARFEELCG DLFRSTIQPV ERVLQDAKMD KRSVHDVVLV GGSTRIPKVQ

351 SLVSDFFGGK ELNKSINPDE AVAYGAAVQA FILTGGKSKQ TEGLLLLDVT

401 PLTLGIETAG GVMTALIKRN TTIPTKKSQI FSTYADNQPG VHIQVFEGER

451 AMTKDCHLLG TFDLSGIPPA PRGVPQIEVT FDLDANGILN VSAEEKGTGK

501 RNQITITNDK GRLSKDEIER MVNDAMKYEE DDKAQRDRVE AKNGLENYAY

551 SMKNTLSDSN VSGKLDDSDK ATLNKEIDAA LEWLSSNQEA TKEEYEHRQK

601 ELESVCNPIM TKMYQSMGGA AGGMPGGMPG GMPDMSGMSG GAGPAGGASS

651 GPKVEEVD 


\section{Mascot Score Histogram}

Protein score is $-10 * \log (\mathrm{P})$, where $\mathrm{P}$ is the probability that the observed match is a random event. Protein scores greater than 83 are significant $(\mathrm{p}<0.05)$. Protein scores are derived from ions scores as a non-probabilistic basis for ranking protein hits.

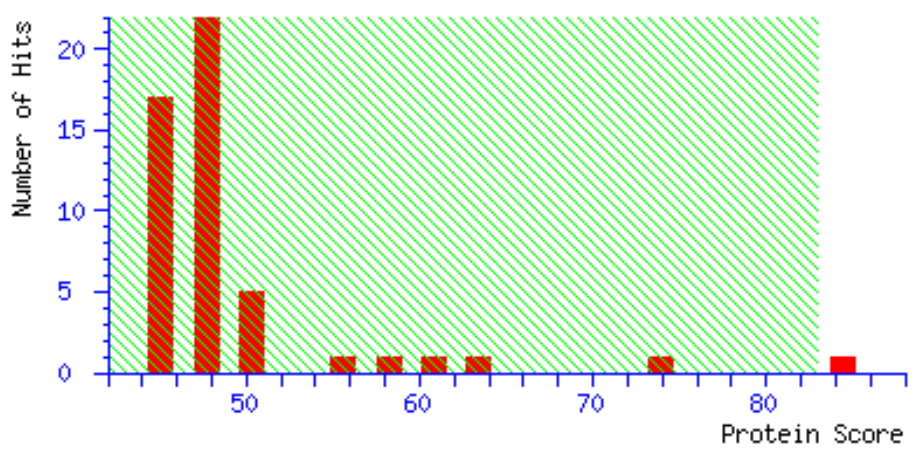

Match to: gi|157864052 Score: 84 Expect: 0.04 dipeptidyl-peptidase III; metallo-peptidase, Clan M-, Family M49 [Leishmania major strain Friedlin] Nominal mass $\left(\mathrm{M}_{\mathrm{r}}\right)$ : 75920; Calculated pI value: 5.30 NCBI BLAST search of gi|157864052 against $\mathrm{nr}$

Unformatted sequence string for pasting into other applications Taxonomy: Leishmania major strain FriedlinLinks to retrieve other entries containing this sequence from NCBI Entrez:gi|68223784 from Leishmania major strain Friedlin Variable modifications: Carbamidomethyl (C),Oxidation (M)Cleavage by Trypsin: cuts C-term side of KR unless next residue is P Sequence Coverage: $\mathbf{2 6 \%}$

Matched peptides shown in Bold:

1 MSHNTLYITP RAVPYCILSI ANAFKDLTPK QRHYAHHMMA AGWCGAPVVA

51 EQLSPESLPL LRLFFKVLSA QPLDTFKANS VNAGVDPDEV DQFLEYFAMV

101 YSNMGNYISF GDTKFVPSIP KERFAKIVAS ADGSPAVDAQ LLDAIYNLDD

151 DKLTLDFPPK GLTRYYSPNV TREDAAVAND FLASKKMDGV NTRVFKEEDG

201 SLVIRVAAAT ERTVPAEKFN GRTIAIYYGD YKEEMARVVA ELRKAQPYAE

251 NETEVRMLNH YIEHFQYGDV EAHKESQKEW VRDVGPTVET NIGFIESYRD

301 PSGVRAEWEG FVAVVNKEQS KMYGALVAQG EKFIAQLPWG KAFEKDVFSS

351 PDFTSLDVLG FASSGIPAGI NIPNYDDIRQ TVGFKNVYLS NVVSAMTFKD

401 KLNYITEADW ELYKASILAA TSVNVGIHEL LGHGTGKLLS ENSDGTFNFD

451 EKTVDPLSGK PVATWYKPGD TYSSVFGGLG SSYEECRAEA VSLYLCLLPE

501 LLEIFNIQTA KEQQDVIYVC WLNMVRAGLV GLEFYTPEKQ QWRQAHMRAR

551 FCILQALARA PNPIVQITEN AKEGVLITLD RERIATDGRQ AIGDLLVNLN

601 VNKATADAKR GSAYFENMTV VSDQYVHYRD IIMARRKPRK QYVQPHTFIS

$\mathbf{6 5 1}$ GDTVEVLEFA GSVEGVVESF VTRHREIPL 